
ISSN 2675-6218

\title{
CARACTERÍSTICAS HIDROGEOMORFOMÉTRICAS E DINÂMICA DA COBERTURA DO SOLO NA MICROBACIA DO RIO ARIRANHA, AMAZÔNIA OCIDENTAL, BRASIL
}

\section{HYDROGEOMORPHOMETRIC CHARACTERISTICS AND DYNAMICS OF LAND COVER IN THE ARIRANHA RIVER MICROBASIN, WESTERN AMAZON, BRAZIL}

Jhony Vendruscolo ${ }^{1}$, Nilson Reinaldo Fernandes dos Santos Junior², Thaiza Martins de Macedo ${ }^{3}$, Miquel Victor Batista Donegá ${ }^{4}$, João Ânderson Fulan ${ }^{5}$, Renato Francisco da Silva Souza ${ }^{6}$, Wanderson Cleiton Schmidt Cavalheiro $^{7}$

e311034

https://doi.org/10.47820/recima21.v3i1.1034

\section{RESUMO}

$\mathrm{O}$ uso e manejo inadequado do solo compromete a integridade dos recursos naturais, e, consequentemente, a possibilidade de desenvolvimento sustentável na região amazônica. Para mitigar esse problema em áreas já impactadas, é necessário um planejamento ambiental que considere as características da paisagem. Em face ao exposto, objetivou-se com o presente trabalho, disponibilizar as informações sobre as características hidrogeomorfométricas e da dinâmica da cobertura do solo na microbacia do rio Ariranha. Os dados foram obtidos por sensoriamento remoto em conjunto com equações. A microbacia tem área de $41,79 \mathrm{~km}^{2}$, perímetro de $39,14 \mathrm{~km}$, forma alongada, altitudes de 186 a $230 \mathrm{~m}$, relevos planos a forte ondulados, 99,62\% da área classificada como de baixa influência na propagação de incêndios e apta a extremamente apta à mecanização agrícola, rede de drenagem dendrítica, presença de rios pequenos com moderadas condições para habitação de peixes, baixa densidade de nascentes, média densidade de drenagem, coeficiente de manutenção elevado, canal principal reto e médio tempo de concentração. De 1984 a 2021, houve o aumento das áreas de espelho d'água e agropecuária, e a redução das áreas de floresta nativa e campo nativo, na microbacia e na zona ripária. A microbacia tem potencial para o desenvolvimento de atividades agropecuárias, contudo, o desmatamento excessivo da vegetação nativa, principalmente na zona ripária, está comprometendo a qualidade e a disponibilidade hídrica. Portanto, é necessário adotar medidas mitigadoras para reduzir o impacto da ação antrópica nos recursos hídricos (ex: recuperação da vegetação nativa na zona ripária).

PALAVRAS-CHAVE: Geotecnologia. Recursos naturais. Planejamento e gestão ambiental.

\begin{abstract}
\footnotetext{
1 Universidade Federal do Amazonas - UFAM

2 Universidade Federal de Rondônia - UNIR

${ }^{3}$ Universidade Federal do Amazonas - UFAM

4 Universidade Federal do Amazonas - UFAM

5 Universidade Federal de São Carlos - UFSCar

${ }^{6}$ Pesquisador bolsista DCTA FAPEAM/UFAM
}

${ }^{7}$ Cavalheiro Engenharia Rural e Empresarial Ltda
\end{abstract}

The inadequate use and management of the soil compromises the integrity of natural resources, and, consequently, the possibility of sustainable development in the Amazon region. To mitigate this problem in areas that have already been impacted, an environmental planning that considers the characteristics of the landscape is necessary. Thus, our objective was to provide information about the hydrogeomorphometric characteristics and the dynamics of land cover in the Ariranha river microbasin. Data was obtained by remote sensing or equations. The microbasin has area of $41.79 \mathrm{~km}^{2}$, perimeter of $39.14 \mathrm{~km}$, elongated shape, altitudes from 186 to $230 \mathrm{~m}$, flat to heavily undulated reliefs, $99.62 \%$ of the area classified as having low influence on the propagation of fires and suitable extremely suitable for agricultural mechanization, dendritic drainage network, presence of small rivers with moderate conditions for fish housing, low density of springs, medium drainage density, high maintenance coefficient, straight main channel and medium time of concentration. From 1984 to 2021, there was an increase in the areas of water and agriculture, and a reduction in the areas of native forest and native grassland, in the microbasin and in the riparian zone. The microbasin has potential for the development 


\section{RECIMA21 - REVISTA CIENTÍFICA MULTIDISCIPLINAR ISSN 2675-6218}

CARACTERÍSTICAS HIDROGEOMORFOMÉTRICAS E DINÂMICA DA COBERTURA DO SOLO NA MICROBACIA DO RIO ARIRANHA, AMAZÔNIA OCIDENTAL, BRASIL Jhony Vendruscolo, Nilson Reinaldo Fernandes dos Santos Junior, Thaiza Martins de Macedo, Miquel Victor Batista Donegá, João Ânderson Fulan, Renato Francisco da Silva Souza, Wanderson Cleiton Schmidt Cavalheiro

of agricultural activities, however, the excessive deforestation of native vegetation, especially in the riparian zone, is compromising the quality and availability of water. Therefore, it is necessary to adopt mitigating measures to reduce the impact of human action on water resources (e.g. recovery of native vegetation in the riparian zone).

KEYWORDS: Geotechnology. Natural resources. Environmental planning and management.

\section{INTRODUÇÃO}

O desmatamento e o uso inadequado do solo degradam os recursos naturais, inviabilizando as atividades agropecuárias. Esse problema pode ser observado em várias microbacias do estado de Rondônia, a exemplo das microbacias dos rios Enganado (MORETO et al., 2021), Paraíso (LIMA et al., 2021), Pirarara (MENDES et al., 2021), Jacuri (PANZA et al., 2020), Rio Nova Gease (PARÉDIO et al., 2021), Manicoré (VENDRUSCOLO et al., 2019), D'Alincourt (SILVA et al., 2019) e Tinguí (SANTOS et al., 2019), e segundo Cavalheiro (2018), pode afetar a qualidade e a disponibilidade de recursos hídricos. O uso inadequado do solo também ocasiona a perda de solo por erosão hídrica, reduzindo a capacidade produtiva das terras (LOMBARDI NETO; BERTONI, 2014). Portanto, é necessário planejar as estratégias de manejo para a conservação destes recursos naturais da região, e o primeiro passo para isso é a identificação da unidade de gestão mais adequada.

Todo o impacto das atividades antrópicas pode ser observado nas microbacias, principalmente os acumulativos (ex: qualidade da água ao longo do rio), tendo em vista que, os estabelecimentos agropecuários localizados próximo ao exutório tendem a receber toda a carga de dejetos ou contaminantes dos estabelecimentos agropecuários localizados na cabeceira. Por esse motivo, as microbacias são consideradas as unidades mais adequadas para o planejamento e gestão dos recursos naturais. Além de considerar a microbacia como unidade de gestão, também é necessário conhecer as características de sua paisagem e a dinâmica de uso e ocupação do solo, para se elaborar um planejamento eficiente. Essas informações podem ser adquiridas em campo, ou por sensoriamento remoto, a segunda metodologia apresenta como vantagens a obtenção de grande quantidade de dados em tempo relativamente curto e com baixo custo financeiro (SOARES et al., 2019), e a possibilidade de cruzar informações para se identificar as regiões mais aptas ao desenvolvimento agropecuário, suscetíveis a degradação e prioritárias para a recuperação (SILVA et al., 2021a).

A microbacia do rio Ariranha abrange 8 estabelecimentos agropecuários privados (INCRA, 2018) e está localizada em uma região conhecida por formar um corredor ecológico (bacia do rio Guaporé) que conecta os biomas Amazônia e Pantanal (SILVA et al., 2015), e por apresentar expansão do agronegócio (Cone Sul de Rondônia) nas últimas décadas (IBGE, 2021). E apesar da importância desta microbacia, existe uma escassez de informações para subsidiar o desenvolvimento sustentável da região. 


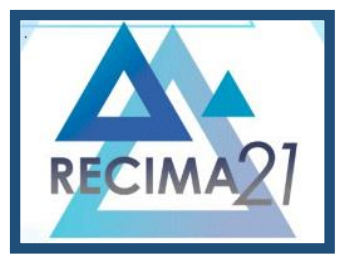

\section{RECIMA21 - REVISTA CIENTÍFICA MULTIDISCIPLINAR ISSN 2675-6218}

CARACTERÍSTICAS HIDROGEOMORFOMÉTRICAS E DINÂMICA DA COBERTURA DO SOLO NA MICROBACIA DO RIO ARIRANHA, AMAZÔNIA OCIDENTAL, BRASIL Jhony Vendruscolo, Nilson Reinaldo Fernandes dos Santos Junior, Thaiza Martins de Macedo, Miquel Victor Batista Donegá, João Ânderson Fulan, Renato Francisco da Silva Souza, Wanderson Cleiton Schmidt Cavalheiro

Em face ao exposto, objetivou-se com este trabalho, disponibilizar informações sobre as características hidrogeomorfométricas e da dinâmica temporal e espacial da cobertura do solo na microbacia do rio Ariranha, Amazônia Ocidental, Brasil.

\section{MATERIAL E MÉTODOS}

\section{Localização e características gerais}

A microbacia do rio Ariranha está localizada na sub-bacia do rio Escondido, município de Cabixi/RO (Figura 1). Essa região tem clima do tipo Monção, temperatura de $24^{\circ} \mathrm{C}$ a $26^{\circ} \mathrm{C}$ (ALVARES et al., 2013), precipitação de 1.728,9 a $1.843,7 \mathrm{~mm}^{2}$ ano-1 $^{-1}$ (FRANCA, 2015), sedimentos inconsolidados (CPRM, 2021) e solos classificados como Neossolos Flúvicos (SEDAM, 2002).

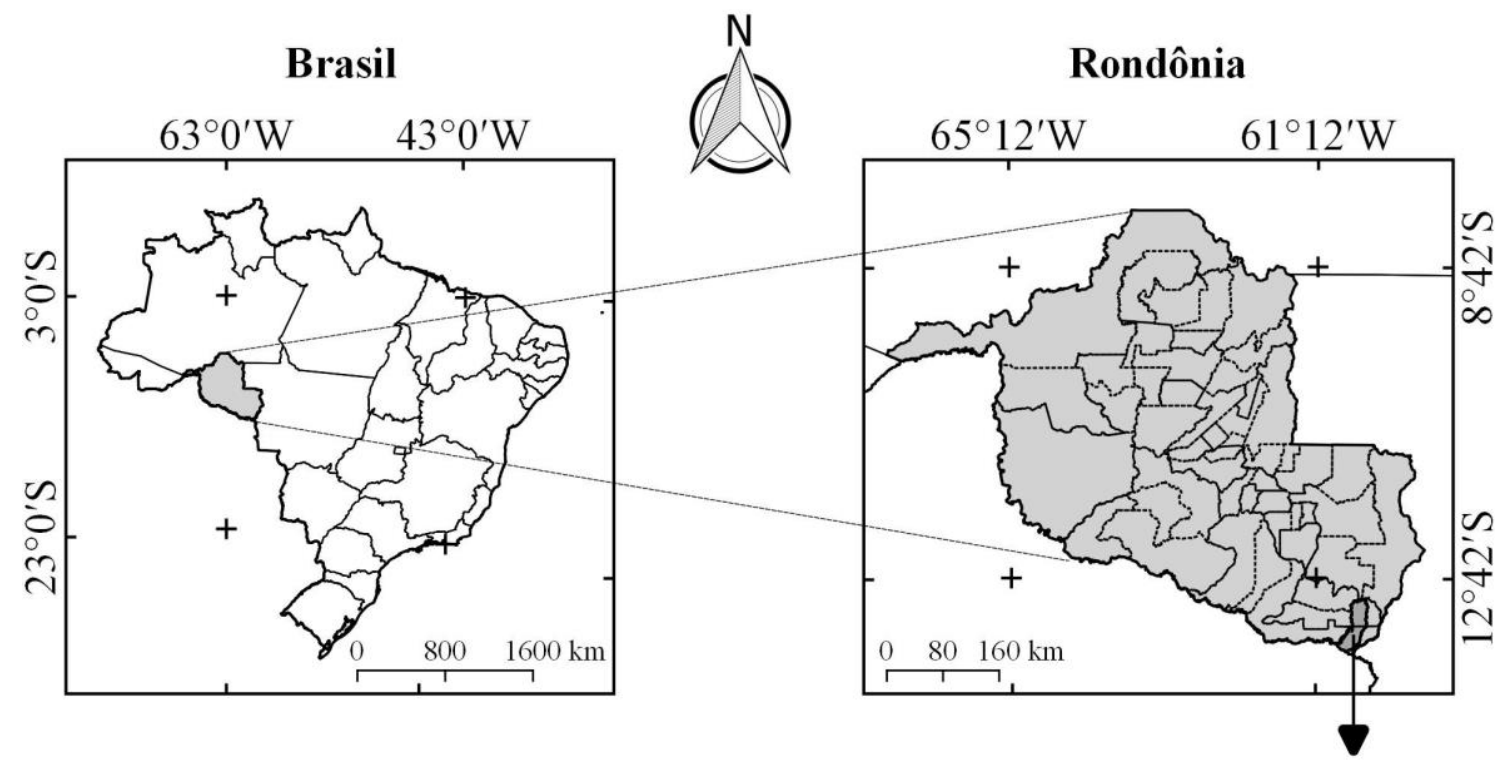

Microbacia do rio Ariranha

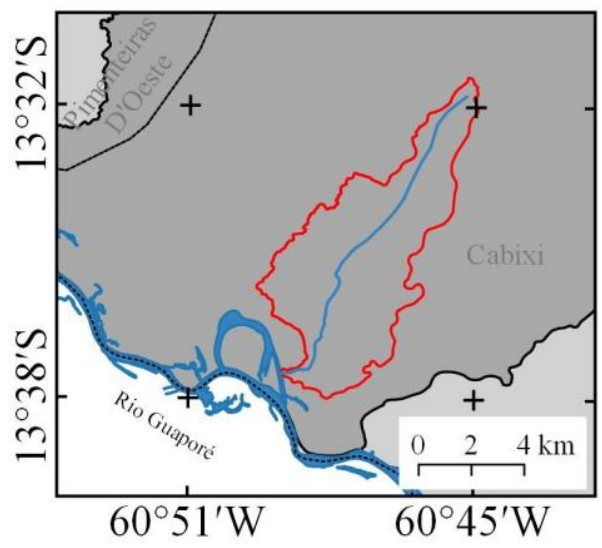

Sub-bacia do rio Escondido

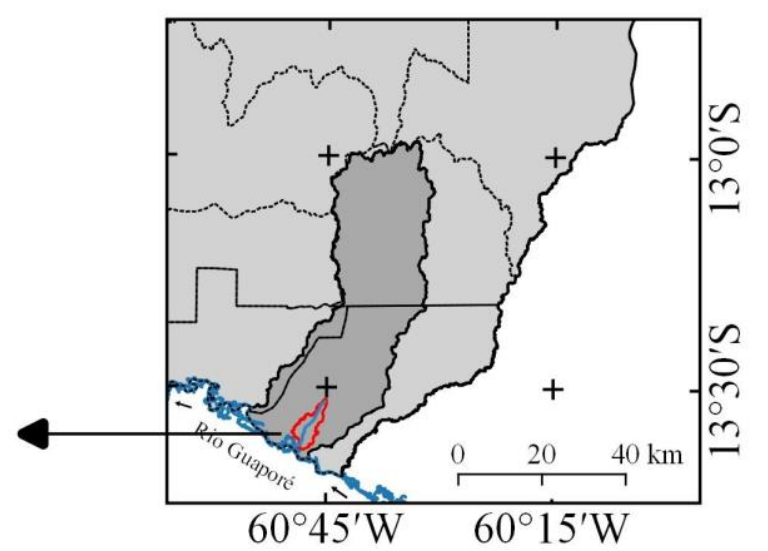

Sistema de Coordenadas Geográficas - Datum WGS 84

Figura 1. Localização da microbacia do rio Ariranha, Amazônia Ocidental, Brasil. 


\section{RECIMA21 - REVISTA CIENTÍFICA MULTIDISCIPLINAR ISSN 2675-6218}

CARACTERÍSTICAS HIDROGEOMORFOMÉTRICAS E DINÂMICA DA COBERTURA DO SOLO NA MICROBACIA DO RIO ARIRANHA, AMAZÔNIA OCIDENTAL, BRASIL Jhony Vendruscolo, Nilson Reinaldo Fernandes dos Santos Junior, Thaiza Martins de Macedo, Miquel Victor Batista Donegá,

Foram analisadas as características geométricas (área, perímetro, fator de forma, índice de circularidade e coeficiente de compacidade), topográficas (altitude e declividade) e hidrográficas (padrão de drenagem, ordem dos rios, densidade de nascentes, densidade de drenagem, coeficiente de manutenção, índice de sinuosidade e tempo de concentração), e a dinâmica temporal e espacial da cobertura do solo. Para a aquisição destas informações e elaboração dos mapas, foram utilizados os softwares QGIS 2.10.1 (versão Pisa), Google Earth e TrackMaker Free, equações, imagens altimétricas registradas pelo satélite ALOS (sensor Palsar) (ASF, 2017) e imagens de cobertura do solo registradas pelos satélites Landsat 5 e Landsat 8 (INPE, 2021). A metodologia foi executada em cinco etapas.

\section{1aㅡ Etapa - Características geométricas}

Área e perímetro da microbacia: inicialmente foi delimitado o perímetro da microbacia utilizando a ferramenta TauDEM (passos: Pit Remove < D8 Flow Directions < D8 Contributing Area $1^{\underline{a}}$ versão) < Stream Definition By Threshold < Edição do ponto de exutório < D8 Contributing Area - $2^{\text {a }}$ versão) e a imagem altimétrica, de forma automática. O arquivo matricial gerado no TauDEM foi transformado para o formato vetorial (ferramenta "poligonizar"), em seguida, dissolvido (ferramenta "dissolver"), suavizado (ferramenta "simplificar geometria") e ajustado no software Google Earth, considerando as características da rede de drenagem e relevo. Após isso, foram calculados a área e o perímetro com a ferramenta "calculadora de campo".

Fator de forma, índice de circularidade e coeficiente de compacidade: estes parâmetros foram calculados com as equações 1 (VILLELA; MATTOS, 1975), 2 (CHRISTOFOLETTI, 1980) e 3 (VILLELA; MATTOS, 1975), e comparados com dados da literatura (Tabela 1).

$F=\frac{A}{L^{2}}$ (Equação 1)

Onde: $\mathrm{F}=$ fator de forma; $\mathrm{A}$ = área da microbacia $\left(\mathrm{km}^{2}\right) ; \mathrm{L}=$ comprimento do eixo da microbacia $(\mathrm{km})$.
$I c=\frac{12,57 x \mathrm{~A}}{P^{2}}$
(Equação 2)

Onde: $\mathrm{Ic}=$ índice de circularidade; $\mathrm{A}=$ área da microbacia $\left(\mathrm{km}^{2}\right) ; \mathrm{P}=$ perímetro da microbacia $(\mathrm{km})$.

$$
K c=0,28 x \frac{P}{\sqrt{ } A}
$$




\title{
RECIMA21 - REVISTA CIENTÍFICA MULTIDISCIPLINAR ISSN 2675-6218
}

\author{
CARACTERÍSTICAS HIDROGEOMORFOMÉTRICAS E DINÂMICA DA COBERTURA DO SOLO NA MICROBACIA \\ DO RIO ARIRANHA, AMAZÔNIA OCIDENTAL, BRASIL \\ Jhony Vendruscolo, Nilson Reinaldo Fernandes dos Santos Junior, Thaiza Martins de Macedo, Miquel Victor Batista Donegá, \\ João Ânderson Fulan, Renato Francisco da Silva Souza, Wanderson Cleiton Schmidt Cavalheiro
}

Onde: $\mathrm{Kc}=$ coeficiente de compacidade; $\mathrm{A}=$ área da microbacia $\left(\mathrm{km}^{2}\right) ; \mathrm{P}=$ perímetro da microbacia $(\mathrm{km})$.

Tabela 1. Classificação dos parâmetros fator de forma, índice de circularidade e coeficiente de compacidade.

\begin{tabular}{|c|c|c|}
\hline Parâmetro & Limite & Classe \\
\hline Fator de forma ${ }^{1}$ & $\begin{array}{c}<0,50 \\
0,50-0,75 \\
0,76-1,00\end{array}$ & $\begin{array}{l}\text { Não sujeito a enchentes } \\
\text { Tendência média a enchentes } \\
\text { Sujeito a enchentes }\end{array}$ \\
\hline Índice de circularidade ${ }^{2}$ & $\begin{array}{c}<0,51 \\
0,51-0,75 \\
0,76-1,00\end{array}$ & $\begin{array}{l}\text { Forma alongada } \\
\text { Forma intermediária } \\
\text { Forma circular }\end{array}$ \\
\hline Coeficiente de compacidade ${ }^{1}$ & $\begin{array}{l}1,00-1,25 \\
1,26-1,50 \\
>1,50\end{array}$ & $\begin{array}{l}\text { Alta propensão a enchentes } \\
\text { Tendência média a enchentes } \\
\text { Não sujeito a enchentes }\end{array}$ \\
\hline
\end{tabular}

Fonte: ${ }^{1}$ LIMA JÚNIOR et al., (2012); ${ }^{2}$ SILVA (2012).

\section{2ㄹ Etapa - Características topográficas}

Altitude: as altitudes mínima e máxima foram obtidas diretamente das imagens altimétricas, e a altitude média foi mensurada com a ferramenta "estatística por zona".

Declividade: mensurada com a ferramenta "modelo digital de elevação", em seguida foi classificada para a aquisição de informações relacionadas ao relevo, influencia na propagação de incêndios e aptidão à mecanização agrícola (Tabela 2). 


\section{RECIMA21 - REVISTA CIENTÍFICA MULTIDISCIPLINAR ISSN 2675-6218}

CARACTERÍSTICAS HIDROGEOMORFOMÉTRICAS E DINÂMICA DA COBERTURA DO SOLO NA MICROBACIA DO RIO ARIRANHA, AMAZÔNIA OCIDENTAL, BRASIL Jhony Vendruscolo, Nilson Reinaldo Fernandes dos Santos Junior, Thaiza Martins de Macedo, Miquel Victor Batista Donegá, João Ânderson Fulan, Renato Francisco da Silva Souza, Wanderson Cleiton Schmidt Cavalheiro

Tabela 2. Classificação do relevo, influência na propagação de incêndios e aptidão à mecanização agrícola em função da declividade (\%).

\begin{tabular}{|c|c|c|}
\hline Parâmetro & Classe & Declividade (\%) \\
\hline Relevo ${ }^{1}$ & $\begin{array}{c}\text { Plano } \\
\text { Suave ondulado } \\
\text { Ondulado } \\
\text { Forte ondulado } \\
\text { Montanhoso } \\
\text { Escarpado }\end{array}$ & $\begin{array}{c}0-3 \\
3-8 \\
8-20 \\
20-45 \\
45-75 \\
>75\end{array}$ \\
\hline $\begin{array}{l}\text { Influência na propagação de } \\
\text { incêndios }^{2}\end{array}$ & $\begin{array}{c}\text { Baixa } \\
\text { Moderada } \\
\text { Alta } \\
\text { Muito alta } \\
\text { Extremamente alta }\end{array}$ & $\begin{array}{c}\leq 15 \\
16-25 \\
26-35 \\
36-45 \\
>45\end{array}$ \\
\hline $\begin{array}{c}\text { Aptidão à mecanização } \\
\text { agrícola }^{3}\end{array}$ & $\begin{array}{l}\text { Extremamente apta } \\
\text { Muito apta } \\
\text { Apta } \\
\text { Moderadamente apta } \\
\text { Não apta }\end{array}$ & $\begin{array}{c}0-5,0 \\
5,1-10,0 \\
10,1-15,0 \\
15,1-20,0 \\
>20,0\end{array}$ \\
\hline
\end{tabular}

Fonte: ${ }^{1}$ SANTOS et al., (2013); ${ }^{2}$ RIBEIRO et al., (2008); ${ }^{3}$ HÖFIG; ARAÚJO-JÚNIOR (2015).

\section{3a Etapa - Características hidrográficas}

Padrão de drenagem, ordem dos rios e nascentes: inicialmente foram gerados os cursos d'água por meio de trilhas, utilizando a ferramenta "adicionar caminho" do software Google Earth. As trilhas foram salvas em formato KML (Keyhole Markup Language), unidas com a ferramenta "Lápis" no software TrackMaker Free e convertidas para o formato Shapefile (SHP) no software QGIS. Em seguida, foi identificado o padrão de drenagem, comparando a distribuição espacial da rede de drenagem da área em estudo com os dados de Parvis (1950), e classificada a ordem dos rios com a ferramenta "strahler". As nascentes foram extraídas com a ferramenta "Stream feature extractor".

Densidade de nascentes, densidade de drenagem, coeficiente de manutenção, índice de sinuosidade e tempo de concentração: estes parâmetros foram calculados com as equações 4 (SANTOS et al., 2012), 5 (HORTON, 1932), 6 (CHRISTOFOLETTI, 1980), 7 (VILLELA; MATTOS, 1975) e 8 (KIRPICH, 1940, apud TARGA et al., 2012). 


\section{RECIMA21 - REVISTA CIENTÍFICA MULTIDISCIPLINAR ISSN 2675-6218}

CARACTERÍSTICAS HIDROGEOMORFOMÉTRICAS E DINÂMICA DA COBERTURA DO SOLO NA MICROBACIA DO RIO ARIRANHA, AMAZÔNIA OCIDENTAL, BRASIL Jhony Vendruscolo, Nilson Reinaldo Fernandes dos Santos Junior, Thaiza Martins de Macedo, Miquel Victor Batista Donegá,

$D n=\frac{N}{A}$

(Equação 4)

Onde: $\mathrm{Dn}=$ densidade de nascentes (nascentes $\mathrm{km}^{-2}$ ); $\mathrm{N}=$ número de nascentes; $\mathrm{A}=$ área da microbacia $\left(\mathrm{km}^{2}\right)$.
$D d=\frac{L}{A}$
(Equação 5)

Onde: $\mathrm{Dd}=$ densidade de drenagem $\left(\mathrm{km} \mathrm{km}^{-2}\right) ; \mathrm{L}=$ comprimento da rede de drenagem $(\mathrm{km}) ; A=$ área da microbacia $\left(\mathrm{km}^{2}\right)$.
$C m=\frac{1}{D d} \times 1000$
(Equação 6)

Onde: $\mathrm{Cm}=$ coeficiente e manutenção $\left(\mathrm{m}^{2} \mathrm{~m}^{-1}\right) ; \mathrm{Dd}=$ densidade de drenagem $\left(\mathrm{km} \mathrm{km}^{-2}\right)$.
$I S=\frac{L-D v}{L} \times 100$
(Equação 7)

Onde: Is = índice de sinuosidade (\%); $L$ = comprimento do canal principal $(\mathrm{km})$; Dv = distância vetorial do canal principal $(\mathrm{km})$.
$T c=57 x\left(\frac{L^{3}}{H}\right)^{0,385}$
(Equação 8)

Onde: Tc = tempo de concentração (minutos); $L$ = comprimento do talvegue principal (km); $H=$ desnível entre a parte mais elevada e a seção de controle $(\mathrm{m})$.

Os parâmetros ordem dos rios, densidade de nascentes, densidade de drenagem e índice de sinuosidade foram classificados de acordo com a literatura (Tabela 3). 


\section{RECIMA21 - REVISTA CIENTÍFICA MULTIDISCIPLINAR ISSN 2675-6218}

CARACTERÍSTICAS HIDROGEOMORFOMÉTRICAS E DINÂMICA DA COBERTURA DO SOLO NA MICROBACIA DO RIO ARIRANHA, AMAZÔNIA OCIDENTAL, BRASIL Jhony Vendruscolo, Nilson Reinaldo Fernandes dos Santos Junior, Thaiza Martins de Macedo, Miquel Victor Batista Donegá,
João Ânderson Fulan, Renato Francisco da Silva Souza, Wanderson Cleiton Schmidt Cavalheiro

Tabela 3. Classificação das características hidrográficas.

\begin{tabular}{|c|c|c|c|}
\hline Parâmetro & Unidade & Classe & Limite \\
\hline Ordem dos rios ${ }^{1}$ & - & $\begin{array}{l}\text { Rio pequeno } \\
\text { Rio médio } \\
\text { Rio Grande }\end{array}$ & $\begin{array}{l}1-3 \\
3-6 \\
7-10\end{array}$ \\
\hline Ordem dos rios ${ }^{2}$ & Unidades & $\begin{array}{l}\text { Improvável habitat de } \\
\text { peixes } \\
\text { Baixas condições } \\
\text { para habitação } \\
\text { Moderadas condições } \\
\text { para habitação } \\
\text { Elevadas condições } \\
\text { para habitação }\end{array}$ & $\begin{array}{c}1 \\
2 \\
3 \\
\geq 4\end{array}$ \\
\hline $\begin{array}{l}\text { Densidade de } \\
\text { nascentes }^{3}\end{array}$ & Nascentes $\mathrm{km}^{-2}$ & $\begin{array}{l}\text { Baixa } \\
\text { Média } \\
\text { Alta } \\
\text { Muito alta }\end{array}$ & $\begin{array}{c}<3 \\
3-7 \\
7-15 \\
>15\end{array}$ \\
\hline $\begin{array}{l}\text { Densidade de } \\
\text { drenagem }{ }^{4}\end{array}$ & $\mathrm{~km} \mathrm{~km}^{-2}$ & $\begin{array}{c}\text { Baixa } \\
\text { Média } \\
\text { Alta } \\
\text { Muito alta }\end{array}$ & $\begin{array}{c}<0,50 \\
0,50-2,00 \\
2,00-3,50 \\
>3,50\end{array}$ \\
\hline Índice de sinuosidade & $\%$ & $\begin{array}{l}\text { Muito reto } \\
\text { Reto } \\
\text { Divagante } \\
\text { Sinuoso } \\
\text { Muito sinuoso }\end{array}$ & $\begin{array}{c}<20 \\
20-29 \\
30-39 \\
40-50 \\
>50\end{array}$ \\
\hline
\end{tabular}

\section{4aㅡ Etapa - Dinâmica da cobertura do solo}

Para a análise da dinâmica de cobertura do solo foram utilizadas as imagens dos satélites Landsat 5 (1984) e Landsat 8 (2021), registradas no período de julho a agosto, em função da melhor qualidade das imagens. Informações sobre as características das imagens dos satélites Landsat 5 e Landsat 8 encontram-se na Tabela 4. 


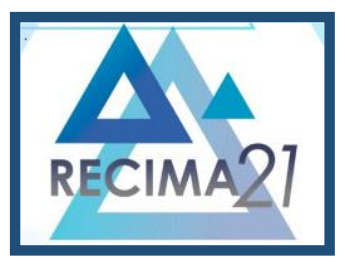

\title{
RECIMA21 - REVISTA CIENTÍFICA MULTIDISCIPLINAR ISSN 2675-6218
}

\author{
CARACTERÍSTICAS HIDROGEOMORFOMÉTRICAS E DINÂMICA DA COBERTURA DO SOLO NA MICROBACIA \\ DO RIO ARIRANHA, AMAZÔNIA OCIDENTAL, BRASIL \\ Jhony Vendruscolo, Nilson Reinaldo Fernandes dos Santos Junior, Thaiza Martins de Macedo, Miquel Victor Batista Donegá, \\ João Ânderson Fulan, Renato Francisco da Silva Souza, Wanderson Cleiton Schmidt Cavalheiro
}

Tabela 4. Características das imagens dos satélites Landsat 5 e Landsat 8, utilizadas para elaboração da dinâmica temporal e espacial da cobertura do solo na microbacia rio Ariranha.

\begin{tabular}{|c|c|c|c|c|c|c|c|c|}
\hline \multirow[b]{2}{*}{ Ano } & \multirow[b]{2}{*}{ Satélite } & \multirow[b]{2}{*}{ Sensor } & \multirow[b]{2}{*}{ B } & \multicolumn{4}{|c|}{ Resolução } & \multirow{2}{*}{$\begin{array}{l}\text { Órbita } \\
\text { Ponto }\end{array}$} \\
\hline & & & & $\begin{array}{l}\text { Espectral } \\
\qquad(\mu \mathrm{m})\end{array}$ & $\begin{array}{l}\text { Espacial } \\
(\mathrm{m})\end{array}$ & $\begin{array}{c}\text { Radiométrica } \\
\text { (bits) }\end{array}$ & $\begin{array}{l}\text { Temporal } \\
\text { (dias) }\end{array}$ & \\
\hline 1984 & $\begin{array}{c}\text { Landsat } \\
5\end{array}$ & TM & $\begin{array}{l}3 \\
4 \\
5\end{array}$ & $\begin{array}{l}0,63-0,69 \\
0,76-0,90 \\
1,55-1,75\end{array}$ & 30 & 8 & 16 & $230 / 69$ \\
\hline 2021 & $\begin{array}{c}\text { Landsat } \\
8\end{array}$ & OLI & $\begin{array}{l}4 \\
5 \\
6\end{array}$ & $\begin{array}{c}0,64-0,67 \\
0,85-0,88 \\
1,57-1,65\end{array}$ & 30 & 16 & 16 & $230 / 69$ \\
\hline
\end{tabular}

B: Banda; TM: Thematic Mapper; OLI: Operational Land Imager.

A cobertura do solo foi classificada de acordo com as principais classes da cobertura da região (água, agropecuária e floresta nativa), nos seguintes passos:

$1^{\circ}$ Passo: mensuração do Índice de Vegetação por Diferença Normalizada (IVDN), com a equação 9.
$I V D N=(I P-V) /(I P+V)$
(Equação 9)

Onde: IP: Infravermelho Próximo (B4 = Landsat 5; B5 = Landsat 8); V: vermelho (B3 = Landsat 5; B4 = Landsat 8).

$2^{\circ}$ Passo: coleta de 30 amostras de pixels em cada imagem IVDN, 10 para cada classe de cobertura do solo.

$3^{\circ}$ Passo: divisão da imagem IVDN em classes com a ferramenta "slicer", e conversão da imagem matricial gerada para formato vetorial, com a ferramenta "poligonizar".

$4^{\circ}$ Passo: comparação da imagem classificada com a imagem falsa cor (R5G4B3 para o Landsat 5, e R6G5B4 para o Landsat 8).

A zona ripária foi delimitada com a ferramenta "Buffer", considerando $50 \mathrm{~m}$ de raio nas nascentes e uma faixa de $30 \mathrm{~m}$ de cada lado dos rios, conforme o estabelecido pela $\mathrm{n}^{\circ} 12.651$ de 2012 (BRASIL, 2012).

\section{5ª Etapa - Elaboração dos mapas}

Para auxiliar a interpretação dos resultados, foram elaborados os mapas de altitude, relevo, rede e ordem de drenagem, distribuição espacial das nascentes, dinâmica espacial e temporal da 


\section{RECIMA21 - REVISTA CIENTÍFICA MULTIDISCIPLINAR ISSN 2675-6218}

CARACTERÍSTICAS HIDROGEOMORFOMÉTRICAS E DINÂMICA DA COBERTURA DO SOLO NA MICROBACIA DO RIO ARIRANHA, AMAZÔNIA OCIDENTAL, BRASIL Jhony Vendruscolo, Nilson Reinaldo Fernandes dos Santos Junior, Thaiza Martins de Macedo, Miquel Victor Batista Donegá,
João Ânderson Fulan, Renato Francisco da Silva Souza, Wanderson Cleiton Schmidt Cavalheiro cobertura do solo na microbacia e na zona ripária, utilizando a ferramenta "novo compositor de impressão", e o Sistema de Coordenadas Geográficas - Datum WGS 84.

\section{RESULTADOS E DISCUSSÃO}

\section{Características geométricas}

A microbacia do rio Ariranha tem área de $41,79 \mathrm{~km}^{2}$, perímetro de $39,14 \mathrm{~km}$, fator de forma de 0,23 , índice de circularidade de 0,34 e coeficiente de compacidade de 1,70. Esses resultados denotam que a microbacia tem formato alongado e não está sujeita a enchentes (Tabela 1). Resultados semelhantes foram observados nas microbacias dos rios São Jorge (PACHECO et al., 2020), Alto Rio Escondido (VENDRUSCOLO et al., 2020a) e Médio Rio Escondido (VENDRUSCOLO et al., 2020b), também pertencentes a sub-bacia do rio Escondido, sendo, portanto, comum na região. Apesar de não estar sujeita a enchentes, do ponto de vista geométrico, existem outros fatores que podem contribuir para a formação de enchentes, como o tempo de concentração e o tipo de cobertura do solo, que serão discutidos posteriormente.

\section{Características topográficas}

Os valores de altitude variam de 186 a $230 \mathrm{~m}$, com valor médio de 203 m e amplitude altimétrica de $44 \mathrm{~m}$ (Figura 2). 


\section{RECIMA21 - REVISTA CIENTÍFICA MULTIDISCIPLINAR ISSN 2675-6218}

CARACTERÍSTICAS HIDROGEOMORFOMÉTRICAS E DINÂMICA DA COBERTURA DO SOLO NA MICROBACIA DO RIO ARIRANHA, AMAZÔNIA OCIDENTAL, BRASIL Jhony Vendruscolo, Nilson Reinaldo Fernandes dos Santos Junior, Thaiza Martins de Macedo, Miquel Victor Batista Donegá, João Ânderson Fulan, Renato Francisco da Silva Souza, Wanderson Cleiton Schmidt Cavalheiro

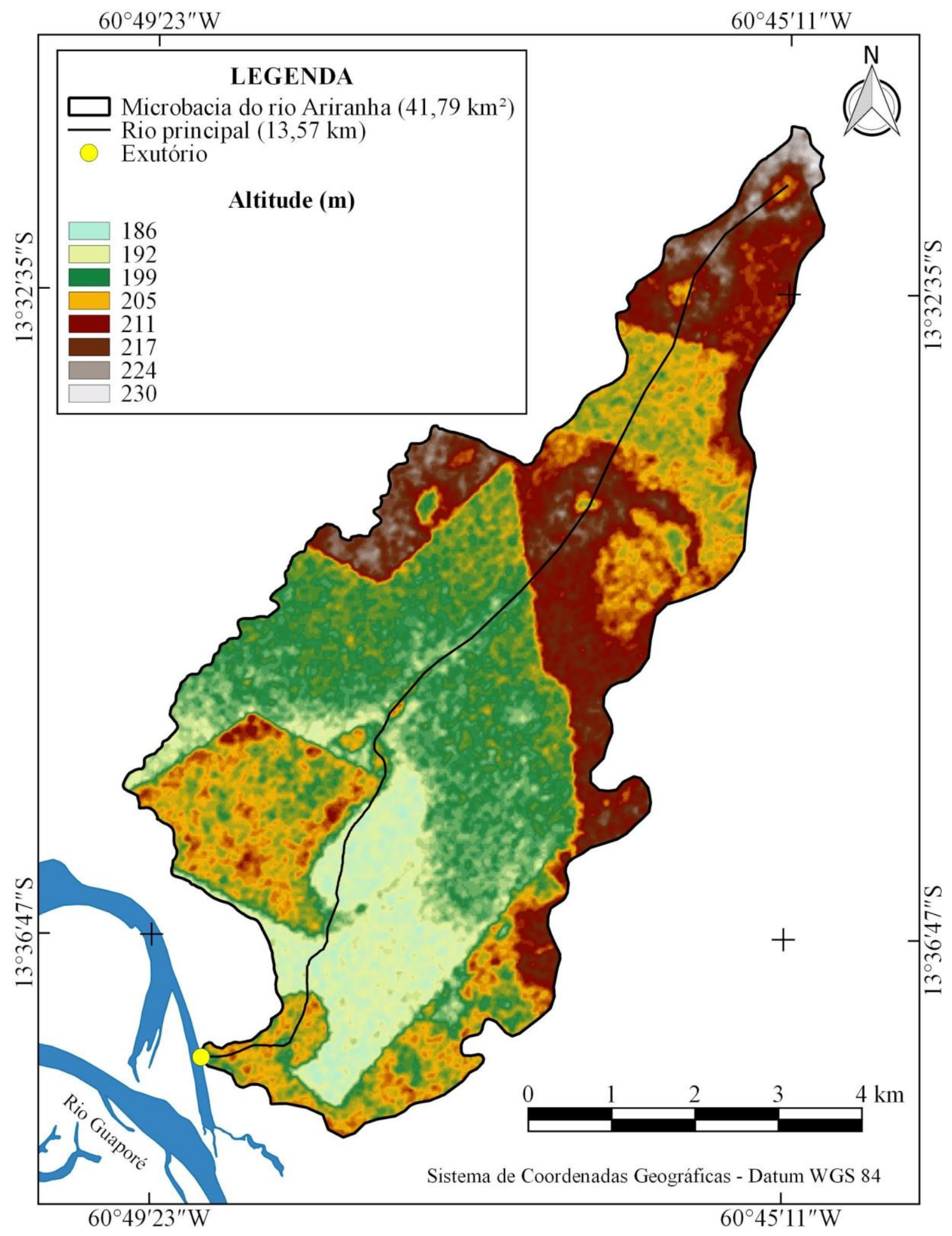

Figura 2. Altitude da microbacia do rio Ariranha, Amazônia Ocidental, Brasil. 


\section{RECIMA21 - REVISTA CIENTÍFICA MULTIDISCIPLINAR ISSN 2675-6218}

CARACTERÍSTICAS HIDROGEOMORFOMÉTRICAS E DINÂMICA DA COBERTURA DO SOLO NA MICROBACIA
DO RIO ARIRANHA, AMAZÔNIA OCIDENTAL, BRASIL
Jhony Vendruscolo, Nilson Reinaldo Fernandes dos Santos Junior, Thaiza Martins de Macedo, Miquel Victor Batista Donegá,
João Ânderson Fulan, Renato Francisco da Silva Souza, Wanderson Cleiton Schmidt Cavalheiro

A altitude é um dos fatores que exerce influência no microclima da região, por afetar a temperatura, precipitação e evapotranspiração (VILLELA; MATTOS, 1975). Logo, a altitude pode ser utilizada para auxiliar na pré-seleção de espécies vegetais de interesse econômico para a região em estudo.

$\mathrm{Na}$ faixa de altitude da microbacia rio Ariranha são encontradas várias espécies vegetais de interesse econômico, incluindo espécies frutíferas como abacate (Persea americana), abacaxi (Ananas comosus), banana (Musa spp.), goiaba (Psidium guajava), graviola (Annona muricata), manga (Mangifera indica), melancia (Citrullus lanatus), laranja (Citrus sinensis), limão (Citrus limon) e rambutã (Nephelium lappaceum), espécies agrícolas como arroz (Oryza sativa), café (Coffea canephora var. robusta), feijão (Phaseolus vulgaris), milho (Zea mays) e soja (Glycine max), espécies olerícolas como abóbora (Cucurbita moschata), agrião (Rorippa nasturtium-aquaticum), batata-doce (Ipomoea batatas), bertalha (Basella alba), beterraba (Beta vulgaris cv. Group Garden Beet), brócolis (Brassica oleracea cv. Group Broccoli), cará (Dioscorea alata), cenoura (Daucus carota), couve-flor (Brassica oleracea cv. Group Cauliflower) e pepino (Cucumis sativus), e espécies florestais como cacau (Theobroma cacao), seringueira (Hevea brasiliensis) e sumaúma (Ceiba pentandra), como pode ser observado no trabalho de Bourke (2010). A grande diversidade de espécies de interesse econômico comprova a possibilidade de implantação de policultivos na microbacia em estudo (sistemas agroflorestais, silvipastoris e agrossilvipastoris) e, consequentemente, a redução do risco financeiro associado aos monocultivos.

A declividade do terreno na microbacia varia de 0 a $35 \%$, formando relevos planos a forte ondulados, contudo, destaca-se o relevo suave ondulado por abranger $60,54 \%$ da área total (Figura 3).

A declividade do terreno influencia as perdas de solo, água e nutrientes, e a seleção de práticas conservacionistas (BERTONI; LOMBARDI NETO, 2014), portanto, a recomendação destas práticas varia de acordo com a classe de relevo (Tabela 5). O solo da microbacia é classificado como Neossolo Flúvico, portanto, recomenda-se o uso integrado de práticas conservacionistas, para aumentar a eficiência no controle do processo erosivo. Os Neossolos Flúvicos são solos derivados de sedimentos aluviais com horizonte $A$ assentado sobre uma camada ou horizonte $C$ e que apresentam caráter flúvico dentro de $150 \mathrm{~cm}$ a partir da superfície do solo (SANTOS et al., 2018). 


\section{PBECMA2]}

\section{RECIMA21 - REVISTA CIENTÍFICA MULTIDISCIPLINAR ISSN 2675-6218}

CARACTERÍSTICAS HIDROGEOMORFOMÉTRICAS E DINÂMICA DA COBERTURA DO SOLO NA MICROBACIA DO RIO ARIRANHA, AMAZÔNIA OCIDENTAL, BRASIL Jhony Vendruscolo, Nilson Reinaldo Fernandes dos Santos Junior, Thaiza Martins de Macedo, Miquel Victor Batista Donegá, João Ânderson Fulan, Renato Francisco da Silva Souza, Wanderson Cleiton Schmidt Cavalheiro

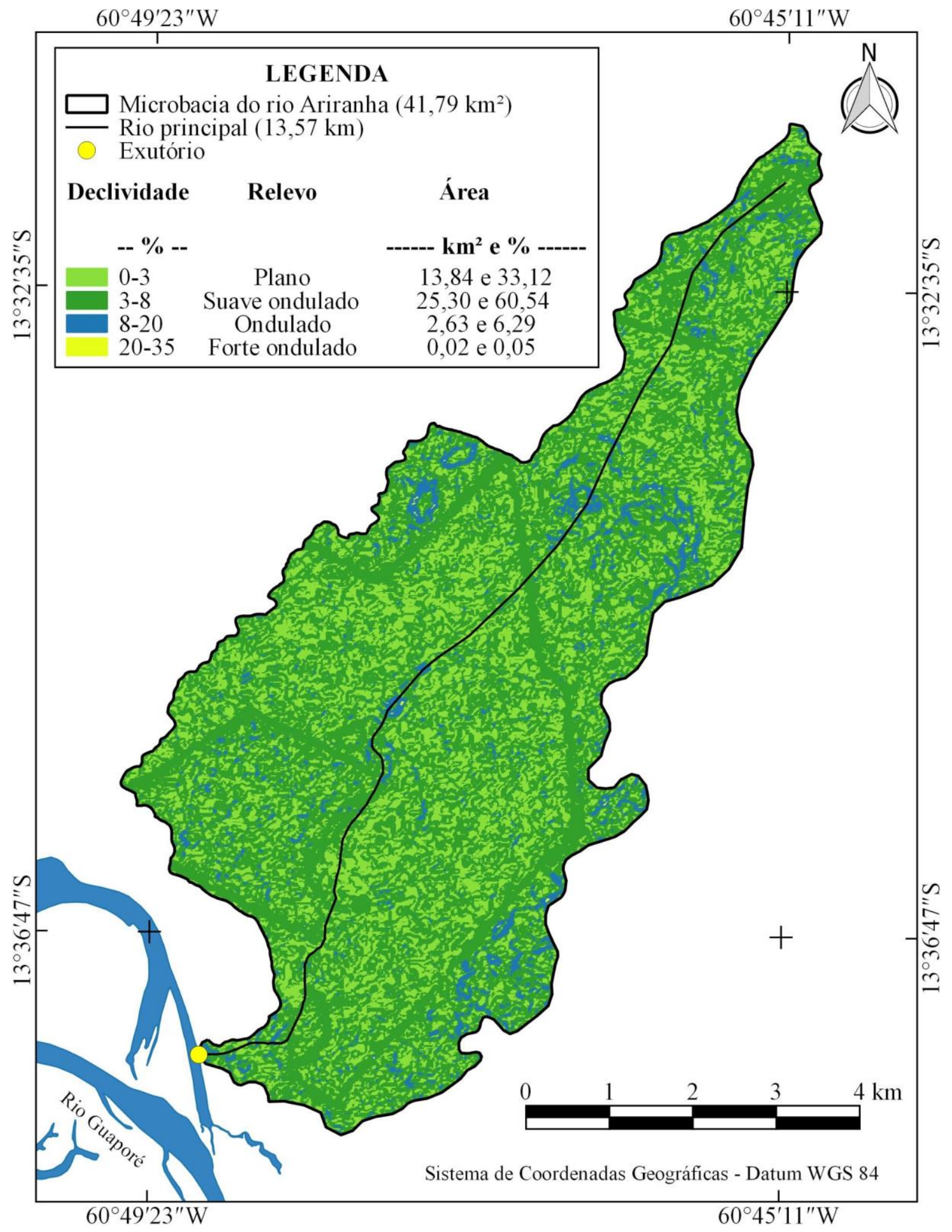

Figura 3. Relevo da microbacia do rio Ariranha, Amazônia Ocidental, Brasil. 


\section{RECIMA21 - REVISTA CIENTÍFICA MULTIDISCIPLINAR ISSN 2675-6218}

CARACTERÍSTICAS HIDROGEOMORFOMÉTRICAS E DINÂMICA DA COBERTURA DO SOLO NA MICROBACIA DO RIO ARIRANHA, AMAZÔNIA OCIDENTAL, BRASIL Jhony Vendruscolo, Nilson Reinaldo Fernandes dos Santos Junior, Thaiza Martins de Macedo, Miquel Victor Batista Donegá, João Ânderson Fulan, Renato Francisco da Silva Souza, Wanderson Cleiton Schmidt Cavalheiro

Tabela 5. Práticas conservacionistas recomendadas para cada classe de relevo na microbacia do rio Ariranha, Amazônia Ocidental, Brasil.

\begin{tabular}{|c|c|}
\hline Classe de relevo & Práticas conservacionistas recomendadas \\
\hline Plano & $\begin{array}{c}\text { Calagem }{ }^{*} \text {, adubação verde, cobertura morta, plantio em contorno e } \\
\text { cultivos em faixa. }\end{array}$ \\
\hline Suave ondulado & $\begin{array}{c}\text { Calagem*, adubação verde, cobertura morta, plantio em contorno, } \\
\text { cultivos em faixa e terraceamento. }\end{array}$ \\
\hline Ondulado & $\begin{array}{l}\text { Calagem*, adubação verde, cobertura morta, plantio em contorno, } \\
\text { cultivos em faixa, cordões de vegetação permanente, controle do fogo, } \\
\text { terraceamento, florestamento e reflorestamento. }\end{array}$ \\
\hline Forte ondulado & $\begin{array}{c}\text { Calagem }{ }^{*} \text {, adubação verde, cobertura morta, plantio em contorno, } \\
\text { cultivos em faixa, cordões de vegetação permanente, controle do fogo, } \\
\text { terraceamento, florestamento e reflorestamento. }\end{array}$ \\
\hline
\end{tabular}

${ }^{*}$ A calagem deve ser realizada com base na análise de solo.

$\mathrm{Na}$ microbacia existem regiões consideradas de baixa $(99,62 \%)$, moderada $(0,36 \%)$ e alta $(0,02 \%)$ influência na propagação de incêndios. A predominância de regiões com baixa influência na propagação de incêndios é importante em estabelecimentos agropecuários, tendo em vista que reduz os riscos de perdas de produção, rebanhos e estruturas físicas (VENDRUSCOLO et al., 2021a).

Com relação à aptidão à mecanização agrícola, observa-se que existem desde regiões extremamente aptas a não aptas, mas dominam as classes extremamente apta (70,59\%), muito apta (26,68\%) e apta (2,37\%), abrangendo $99,64 \%$ da área total quando somadas. Esse resultado confirma o potencial para a mecanização agrícola da região, principalmente para os cultivos de milho e soja em grande escala, por exigirem colheita mecanizada. O cultivo mecanizado destas culturas já é uma realidade no município de Cabixi, o qual ocupou no ano de 2019 a 5 $5^{\underline{a}}$ e a $6^{\underline{a}}$ posição de maiores áreas plantadas de milho (20.020 ha) e soja (24.630 ha) no estado de Rondônia, respectivamente (IBGE, 2021).

\section{Características hidrográficas}

A microbacia tem rede de drenagem com comprimento de $36,09 \mathrm{~km}$, padrão dendrítico, rios de $3^{\text {a }}$ ordem (Figura 4), 15 nascentes (Figura 5), 0,36 nascentes $\mathrm{km}^{-2}$, densidade de drenagem de 0,86 $\mathrm{km} \mathrm{km}^{-2}$, coeficiente de manutenção de $1.157,9 \mathrm{~m}^{2} \mathrm{~m}^{-1}$, índice de sinuosidade de $7,15 \%$ e tempo de concentração de $7,42 \mathrm{~h}$. 


\section{RECIMA21 - REVISTA CIENTÍFICA MULTIDISCIPLINAR ISSN 2675-6218}

CARACTERÍSTICAS HIDROGEOMORFOMÉTRICAS E DINÂMICA DA COBERTURA DO SOLO NA MICROBACIA DO RIO ARIRANHA, AMAZÔNIA OCIDENTAL, BRASIL Jhony Vendruscolo, Nilson Reinaldo Fernandes dos Santos Junior, Thaiza Martins de Macedo, Miquel Victor Batista Donegá, João Ânderson Fulan, Renato Francisco da Silva Souza, Wanderson Cleiton Schmidt Cavalheiro

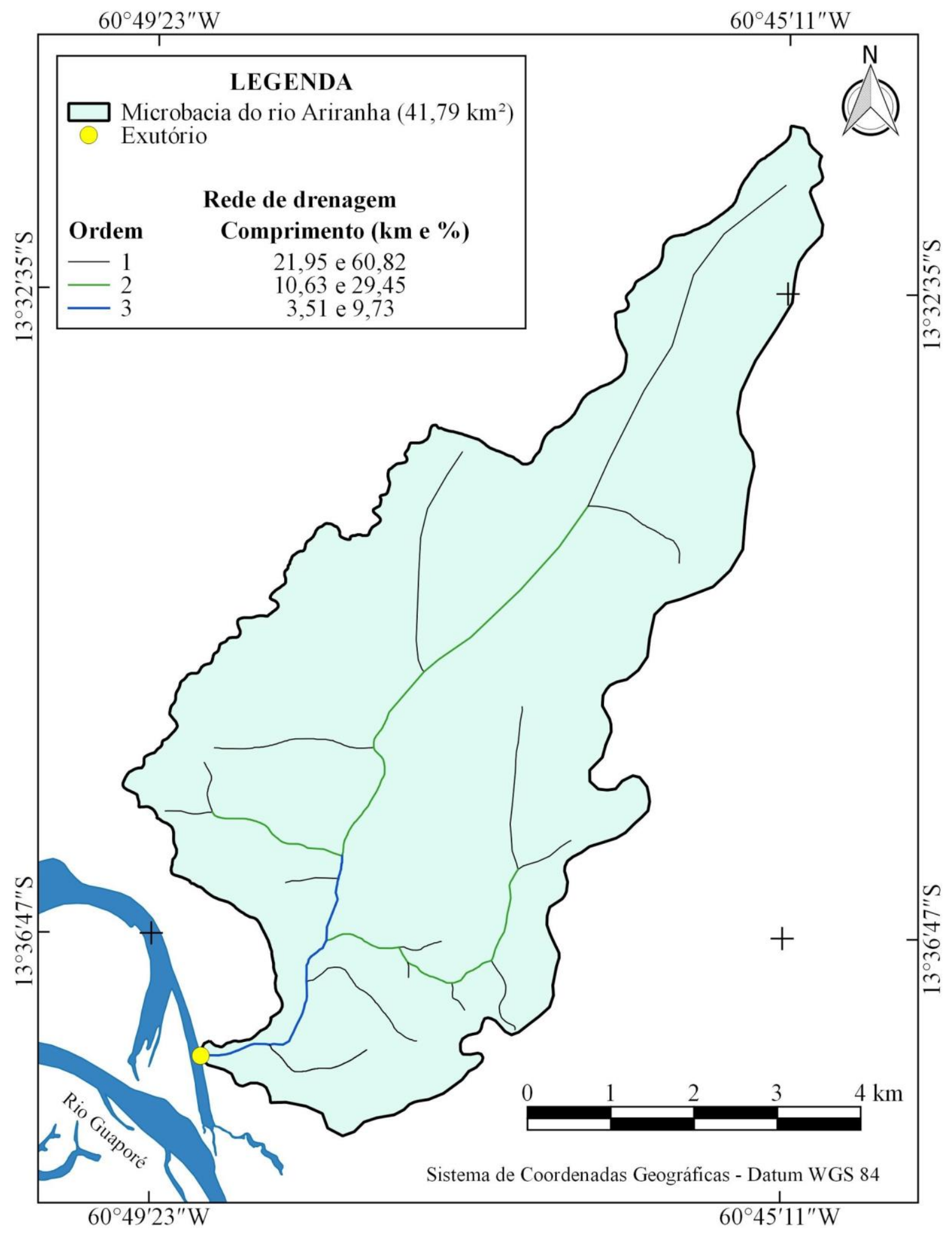

Figura 4. Rede e ordem de drenagem da microbacia do rio Ariranha, Amazônia Ocidental, Brasil. 


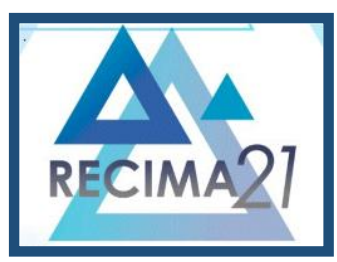

\section{RECIMA21 - REVISTA CIENTÍFICA MULTIDISCIPLINAR ISSN 2675-6218}

CARACTERÍSTICAS HIDROGEOMORFOMÉTRICAS E DINÂMICA DA COBERTURA DO SOLO NA MICROBACIA DO RIO ARIRANHA, AMAZÔNIA OCIDENTAL, BRASIL Jhony Vendruscolo, Nilson Reinaldo Fernandes dos Santos Junior, Thaiza Martins de Macedo, Miquel Victor Batista Donegá, João Ânderson Fulan, Renato Francisco da Silva Souza, Wanderson Cleiton Schmidt Cavalheiro

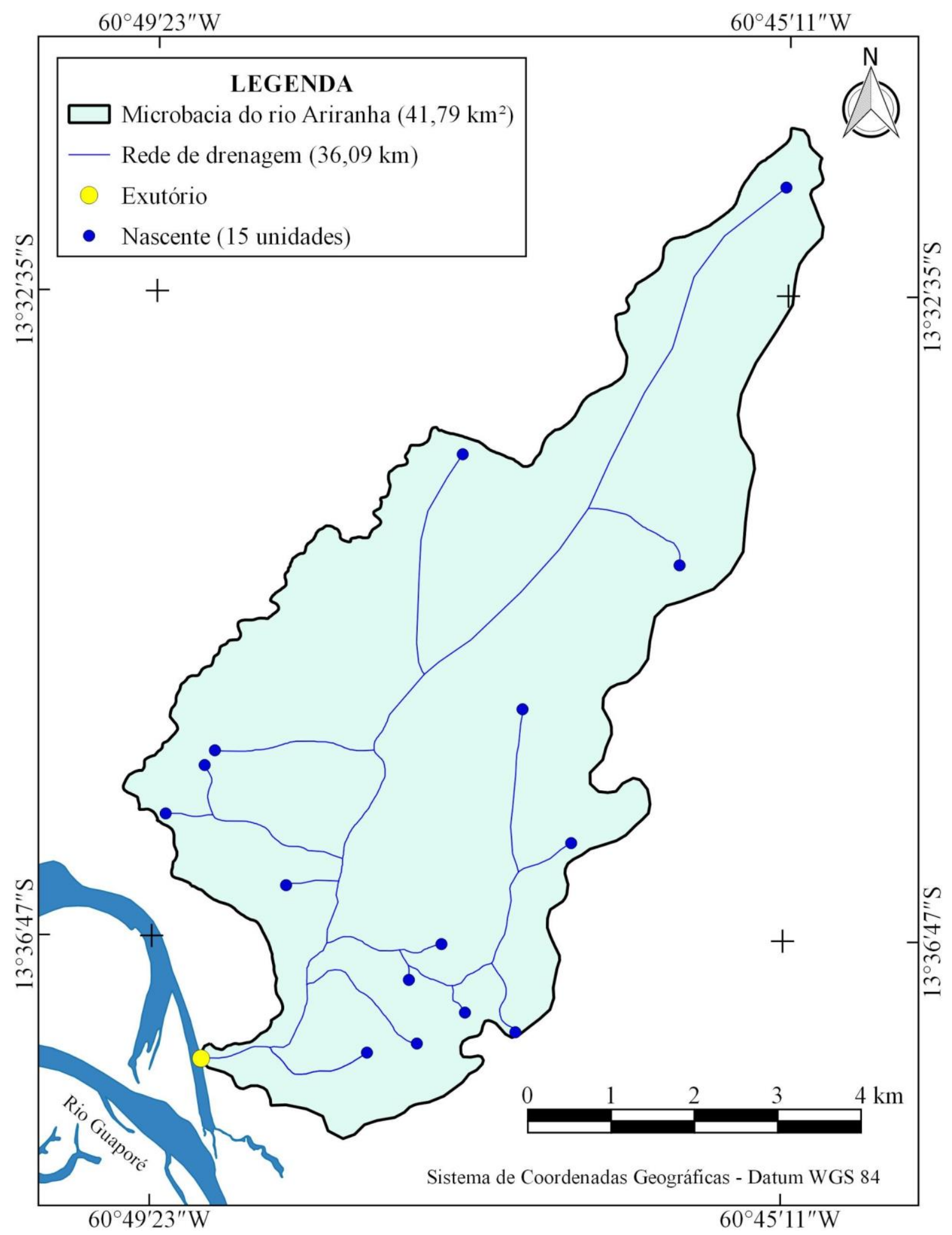

Figura 5. Distribuição espacial das nascentes na microbacia do rio Ariranha,

Amazônia Ocidental, Brasil. 


\section{RECIMA21 - REVISTA CIENTÍFICA MULTIDISCIPLINAR ISSN 2675-6218}

CARACTERÍSTICAS HIDROGEOMORFOMÉTRICAS E DINÂMICA DA COBERTURA DO SOLO NA MICROBACIA DO RIO ARIRANHA, AMAZÔNIA OCIDENTAL, BRASIL Jhony Vendruscolo, Nilson Reinaldo Fernandes dos Santos Junior, Thaiza Martins de Macedo, Miquel Victor Batista Donegá, João Ânderson Fulan, Renato Francisco da Silva Souza, Wanderson Cleiton Schmidt Cavalheiro

O padrão de drenagem dendrítico se forma quando os rios fluem sobre rochas consideradas homogêneas do ponto de vista horizontal, permitindo a formação de erosões similares em todas as direções (PARVIS, 1950). No caso da microbacia do rio Ariranha, o padrão de drenagem se formou sobre sedimentos inconsolidados (CPRM, 2021), material que também apresenta característica homogênea, do ponto de vista horizontal.

A ordem de drenagem indica a formação de um rio principal de porte pequeno e com moderadas condições para habitação de peixes. Portanto, essa região não é recomendada para o desenvolvimento da piscicultura. Esse resultado diverge daquele encontrado em outras microbacias pertencentes à bacia do Guaporé e sub-bacia do rio Escondido, por exemplo, microbacias do Alto rio Escondido (VENDRUSCOLO et al., 2020a), Médio Rio Escondido (VENDRUSCOLO et al., 2020b) e Enganado (MORETO et al., 2019).

As densidades de nascentes e drenagem são consideradas baixa e média, respectivamente. A microbacia tem toda a sua área composta por sedimentos inconsolidados, como areia, silte, argila e cascalho (CPRM, 2021), que resultam em alta permeabilidade do solo, logo, existe pouco escoamento superficial. De acordo com Guerra (1997), o escoamento superficial é responsável pela formação de sulcos que evoluem para ravina e posteriormente para voçoroca, como o passar do tempo, se a profundidade alcançar o lençol freático formam-se novas nascentes e novos cursos d'água. Portanto, a presença de sedimentos inconsolidados explica a baixa densidade de nascentes e a média densidade de drenagem.

O valor do coeficiente de manutenção da microbacia do rio Ariranha é considerado alto, quando comparado com os coeficientes de manutenção das microbacias Alto Rio Escondido $\left(234,1 \mathrm{~m}^{2} \mathrm{~m}^{-1}\right)$ (VENDRUSCOLO et al., 2020a), Médio Rio Escondido (246 $\mathrm{m}^{2} \mathrm{~m}^{-1}$ ) (VENDRUSCOLO et al., 2020b), Enganado (347,2 $\mathrm{m}^{2} \mathrm{~m}^{-1}$ ) (MORETO et al., 2019) e São Jorge $\left(563,0 \mathrm{~m}^{2} \mathrm{~m}^{-1}\right.$ ) (PACHECO et al., 2020). $O$ alto valor de coeficiente de manutenção da microbacia do rio Ariranha também está associado com os sedimentos inconsolidados, visto que não favorecem a formação de cursos d'água e, consequentemente, o aumento da densidade de drenagem. É importante salientar que o valor do coeficiente de manutenção aumenta com a redução da densidade de drenagem (Equação 6).

O índice de sinuosidade que o canal principal do rio Ariranha possui é muito reto (Tabela 3), e está associado com a presença de sedimentos inconsolidados que não apresentam resistência física o suficiente para redirecionar o fluxo hídrico e formar os meandros do rio. Esse tipo de canal também pode ser observado nas microbacias dos rios Jacuri (PANZA et al., 2020) e Gavião (DONEGÁ et al., 2021), ambas localizadas na bacia do rio Guaporé.

O tempo de concentração é considerado baixo, uma vez que a duração da precipitação na região pode exceder o tempo de 7,42 h. Com base no trabalho de Fietz et al. (2011), constata-se que 


\section{RECIMA21 - REVISTA CIENTÍFICA MULTIDISCIPLINAR ISSN 2675-6218}

CARACTERÍSTICAS HIDROGEOMORFOMÉTRICAS E DINÂMICA DA COBERTURA DO SOLO NA MICROBACIA DO RIO ARIRANHA, AMAZÔNIA OCIDENTAL, BRASIL Jhony Vendruscolo, Nilson Reinaldo Fernandes dos Santos Junior, Thaiza Martins de Macedo, Miquel Victor Batista Donegá, João Ânderson Fulan, Renato Francisco da Silva Souza, Wanderson Cleiton Schmidt Cavalheiro

a cada 2 anos podem ocorrer chuvas com intensidade de 15,88 $\mathrm{mm} \mathrm{h}^{-1}$. Logo, podem ocorrer vazões de até $184,34 \mathrm{~m}^{3} \mathrm{~s}^{-1}$ na microbacia, e, consequentemente, enchentes de grandes magnitudes. Outro fator que contribui para o alagamento da microbacia é a sua localização, visto que está às margens do rio Guaporé e, segundo Santos e Mota (2017), dentro da região conhecida como Pantanal do Guaporé.

\section{Dinâmica temporal e espacial da cobertura do solo (1984 e 2021)}

$\mathrm{Na}$ microbacia, ocorreu a redução das áreas de floresta nativa e campo nativo, os quais passaram de 35,79 e 3,18 $\mathrm{km}^{2}$ no ano de 1984, para 0,00 e 9,69 $\mathrm{km}^{2}$ no ano de 2021 (Figura 6). Também foi observado que houve aumento das áreas de agropecuária e água, passando de 1,48 e $1,24 \mathrm{~km}^{2}$ no ano de 1984, para 30,41 e 1,69 $\mathrm{km}^{2}$ no ano de 2021 (Figura 6).

$\mathrm{Na}$ zona ripária, observou-se uma dinâmica da cobertura do solo semelhante à ocorrida na microbacia (Figura 7). No último ano de análise (2021), a cobertura do solo era composta por 39,21\% de água, 35,27\% de agropecuária e 25,52\% de floresta nativa, não havendo, portanto, área de campo nativo.

Essa dinâmica da cobertura do solo, com avanço constante da agropecuária sobre a cobertura de vegetação nativa (floresta nativa e campo nativo), inclusive nas áreas protegidas legalmente (zonas ripárias), é um cenário bastante comum nas microbacias do estado de Rondônia, sendo constatado nas microbacias dos rios Acará (CARDOSO et al., 2021), Alto Alegre (ROCHA et al., 2021), Alto Rio Branco (VENDRUSCOLO et al., 2021b), Brilhante (FERREIRA et al., 2021), Capivara (PACHECO et al., 2021), Lambari (SANTOS JÚNIOR et al., 2021), Mandi-prata (SANCHES et al., 2021), Nova Gease (PARÉDIO et al., 2021), Paraíso (LIMA et al., 2021), Sabiá (CAVALHEIRO et al., 2021), Segredo (SILVA et al., 2021b) e Tambiú (BARBOSA et al., 2021), todas considerando um intervalo temporal de 30 anos (1988 a 2018), período próximo ao do presente estudo.

As instituições ambientais apresentam fragilidades pela falta de capacidades operacionais para fazer cumprir a legislação, em especial na região amazônica, uma vez que, desde a promulgação da Lei de Proteção da Vegetação Nativa (LPVN) até o atual momento, não houve nenhuma ação coordenada (ex: programa) para fortalecer a gestão organizacional dos órgãos estaduais (ROCHA; SILVA, 2019). Logo, os resultados da dinâmica de cobertura constatados na microbacia do rio Ariranha, assim como para as demais microbacias citadas anteriormente, reforçam a fragilidade do poder público em fazer cumprir a legislação, gerando uma série de impactos ambientais. 


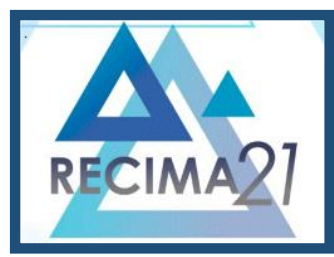

\section{RECIMA21 - REVISTA CIENTÍFICA MULTIDISCIPLINAR ISSN 2675-6218}

CARACTERÍSTICAS HIDROGEOMORFOMÉTRICAS E DINÂMICA DA COBERTURA DO SOLO NA MICROBACIA DO RIO ARIRANHA, AMAZÔNIA OCIDENTAL, BRASIL Jhony Vendruscolo, Nilson Reinaldo Fernandes dos Santos Junior, Thaiza Martins de Macedo, Miquel Victor Batista Donegá, João Ânderson Fulan, Renato Francisco da Silva Souza, Wanderson Cleiton Schmidt Cavalheiro

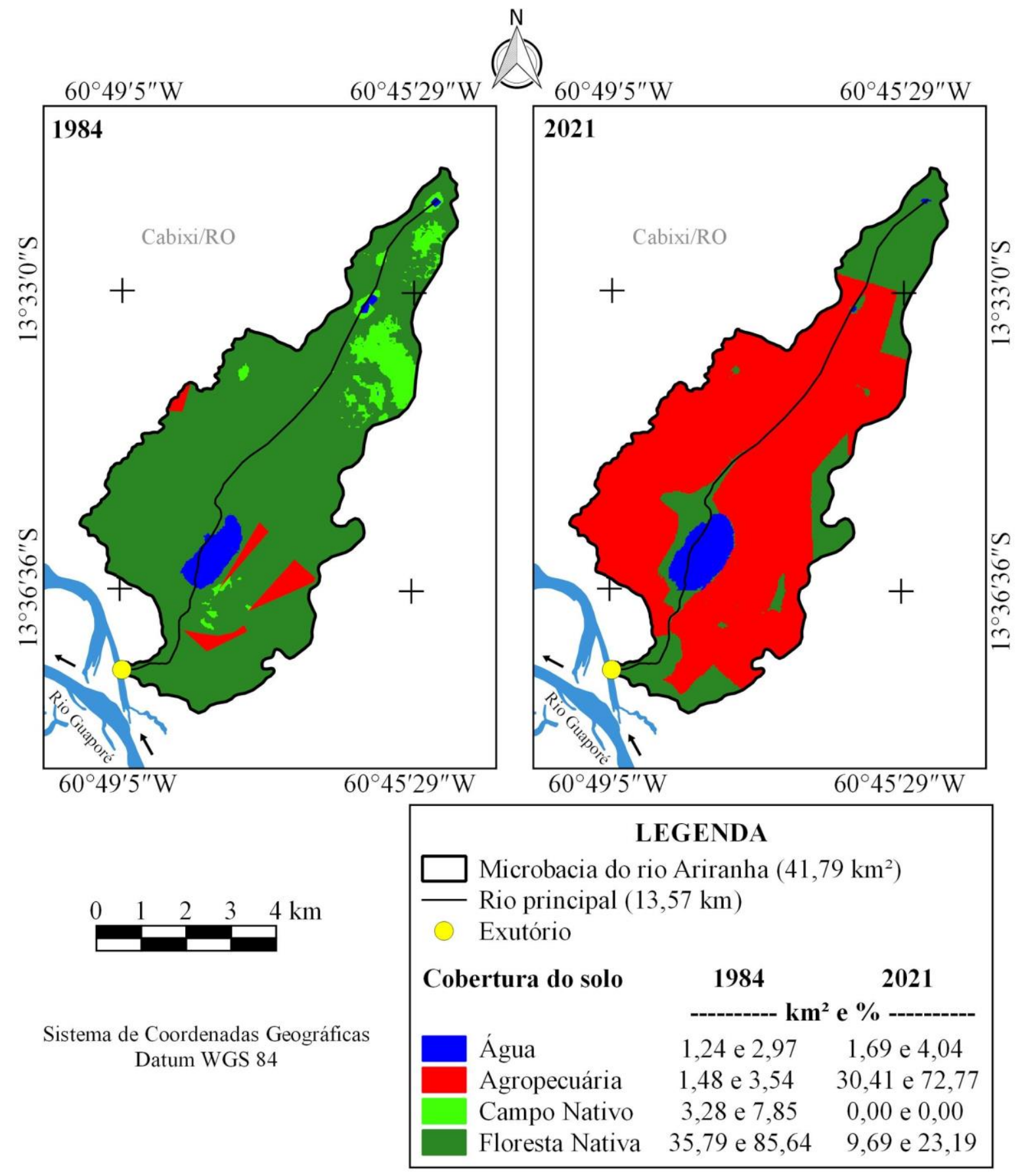

Figura 6. Dinâmica espacial e temporal da cobertura do solo na microbacia do rio Ariranha, Amazônia Ocidental, Brasil. 


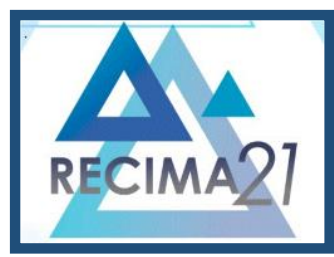

\section{RECIMA21 - REVISTA CIENTÍFICA MULTIDISCIPLINAR ISSN 2675-6218}

CARACTERÍSTICAS HIDROGEOMORFOMÉTRICAS E DINÂMICA DA COBERTURA DO SOLO NA MICROBACIA DO RIO ARIRANHA, AMAZÔNIA OCIDENTAL, BRASIL Jhony Vendruscolo, Nilson Reinaldo Fernandes dos Santos Junior, Thaiza Martins de Macedo, Miquel Victor Batista Donegá, João Ânderson Fulan, Renato Francisco da Silva Souza, Wanderson Cleiton Schmidt Cavalheiro

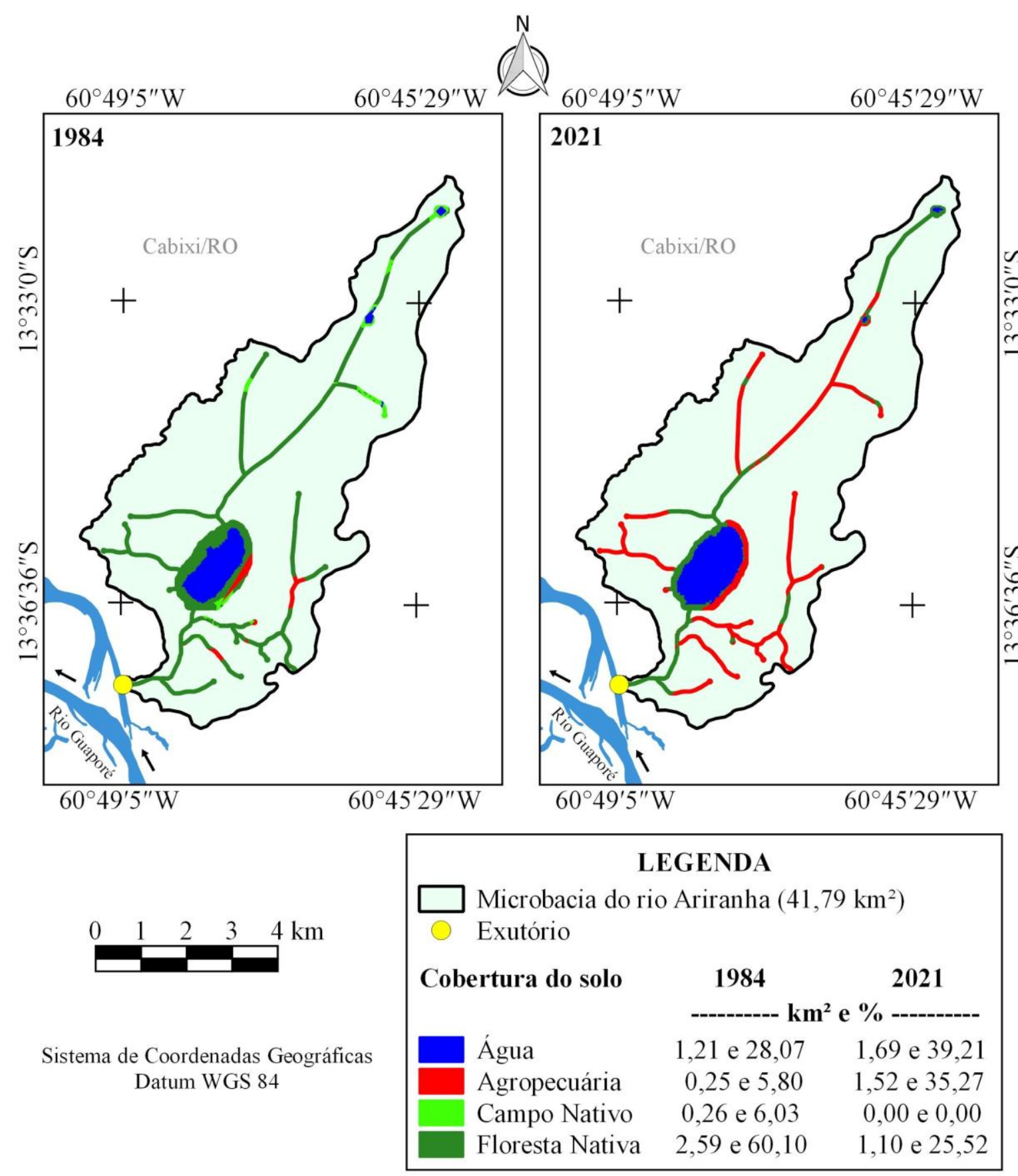

Figura 7. Dinâmica espacial e temporal da cobertura do solo na zona ripária da microbacia do rio Ariranha, Amazônia Ocidental, Brasil.

Um dos principais impactos ambientais decorrentes deste cenário de dinâmica de ocupação do solo na paisagem, é o comprometimento da manutenção de água em quantidade e qualidade para 


\section{RECIMA21 - REVISTA CIENTÍFICA MULTIDISCIPLINAR ISSN 2675-6218}

CARACTERÍSTICAS HIDROGEOMORFOMÉTRICAS E DINÂMICA DA COBERTURA DO SOLO NA MICROBACIA DO RIO ARIRANHA, AMAZÔNIA OCIDENTAL, BRASIL Jhony Vendruscolo, Nilson Reinaldo Fernandes dos Santos Junior, Thaiza Martins de Macedo, Miquel Victor Batista Donegá, João Ânderson Fulan, Renato Francisco da Silva Souza, Wanderson Cleiton Schmidt Cavalheiro

atender as demandas das futuras gerações, tendo em vista que a vegetação nativa exerce diferentes funções eco-hidrológicas (TAMBOSI et al., 2015). Neste contexto, constata-se a necessidade de recuperação da vegetação nativa nas áreas protegidas por lei (Reservas Legais e Zona Ripária), e adoção de sistemas produtivos de menor impacto nos recursos naturais, a exemplo de sistemas agroflorestais e reflorestamentos. Vale salientar que a microbacia está localizada no Pantanal do Guaporé, logo, são necessárias espécies florestais adaptadas à região para se alcançar o sucesso nos florestamentos e reflorestamentos.

\section{CONSIDERAÇÕES FINAIS}

A microbacia do rio Ariranha tem área de $41,79 \mathrm{~km}^{2}$, perímetro $39,14 \mathrm{~km}$, formato alongado, altitude de 186 a 230 m, com predominância do relevo suave ondulado, 99,62\% de área com baixa influência na propagação de incêndios, 99,64\% de área apta a extremamente apta a mecanização agrícola, padrão de drenagem dendrítico de $3^{\underline{a}}$ ordem, baixa densidade de nascentes, densidade de drenagem média, alto coeficiente de manutenção, canal principal muito reto e baixo tempo de concentração (7,42 h).

Entre os anos de 1984 a 2021, houve redução constante das áreas de floresta nativa e campo nativo, tanto na microbacia como em sua zona ripária, restando apenas 23,19\% e 25,52\% da área de floresta nativa na microbacia e zona ripária, respectivamente. No ano de 2021, não havia mais área de campo nativo. Por outro lado, constatou-se o avanço da cobertura de agropecuária, ocupando 72,77\% da área da microbacia e 35,27\% da área da zona ripária em 2021.

As características hidrogeomorfométricas e a dinâmica da cobertura do solo, revelaram a presença de áreas com potencial para o desenvolvimento de atividades econômicas na microbacia do rio Ariranha como, por exemplo, as atividades de agricultura e pecuária, todavia, o cenário atual da cobertura do solo pode comprometer a manutenção da quantidade e qualidade dos recursos hídricos para as gerações futuras. Logo, é recomendado a execução de ações visando a recomposição da vegetação nativa desta microbacia, principalmente em sua zona ripária. Além disso, é fundamental que sejam realizadas práticas de manejo conservacionista do solo e da água em conjunto as atividades de agropecuária, tanto de caráter vegetativo, como edáfico e mecânico, com o intuito de favorecer a infiltração de água no solo e mitigar os impactos decorrentes do escoamento superficial, visando alcançar o desenvolvimento sustentável nesta região.

\section{REFERÊNCIAS}

ALVARES, C. A.; STAPE, J. L.; SENTELHAS, P. C.; GONÇALVES, L. M.; SPAROVEK, G. Köppen's climate classification map for Brazil. Meteorologische Zeitschrift, v. 22, n. 6, p. 711-728, 2013. DOI: http://dx.doi.org/10.1127/0941-2948/2013/0507 


\section{RECIMA21 - REVISTA CIENTÍFICA MULTIDISCIPLINAR ISSN 2675-6218}

CARACTERÍSTICAS HIDROGEOMORFOMÉTRICAS E DINÂMICA DA COBERTURA DO SOLO NA MICROBACIA DO RIO ARIRANHA, AMAZÔNIA OCIDENTAL, BRASIL Jhony Vendruscolo, Nilson Reinaldo Fernandes dos Santos Junior, Thaiza Martins de Macedo, Miquel Victor Batista Donegá, João Ânderson Fulan, Renato Francisco da Silva Souza, Wanderson Cleiton Schmidt Cavalheiro

ASF - Alaska Satellite Facility. Imagem altimétrica. Fairbanks, AK: ASF, 20[--]. Disponível em: https://www.asf.alaska.edul. Acesso em: 15 agosto de 2017.

BARBOSA, D. D.; CAVALHEIRO, W. C. S.; SANTOS JÚNIOR, N. R. F.; SOUZA, R. F. S.; VENDRUSCOLO, J. Características da paisagem para subsidiar o manejo dos recursos naturais na microbacia Tambiú, Amazônia Ocidental, Brasil. Geografía y Sistemas de Información Geográfica, v. 13, n. 20, Sección I: p. 1-23, 2021. Disponível em: https://revistageosig.wixsite.com/geosig/geosig20-2021. Acesso em: 26 nov. 2021.

BELTRAME, A. V. Diagnóstico do meio ambiente físico de bacias hidrográficas: modelo de aplicação. Florianópolis-SC: Universidade Federal de Santa Catarina, 1994.

BERTONI, J.; LOMBARDI NETO, F. Conservação do solo. 9. ed. São Paulo, SP: Ícone, 2014.

BOURKE, R. M. Altitudinal limits of 230 economic crop species in Papua New Guinea. In: HABERLE, S. G.; STEVENSON, J.; PREBBLE, M. (Eds). Altered Ecologies: fire, climate and human influence on terrestrial landscapes. Canberra: ANU E-Press, 2010. p. 473-512.

BRASIL. Lei $\mathbf{n}^{\circ}$ 12.651, de 25 de maio de 2012. Dispõe sobre a proteção da vegetação nativa; altera as Leis nos 6.938, de 31 de agosto de 1981, 9.393, de 19 de dezembro de 1996, e 11.428, de 22 de dezembro de 2006; revoga as Leis nos 4.771, de 15 de setembro de 1965, e 7.754, de 14 de abril de 1989, e a Medida Provisória no 2.166-67, de 24 de agosto de 2001; e dá outras providências. Brasília: Casa Civil, 2012. Disponível em http://www.planalto.gov.br/ccivil 03/ ato20112014/2012/lei/l12651.htm. Acesso em: 4 de julho de 2021.

CARDOSO, L. A. P.; SILVA, E. C.; SANTOS, A. A.; PRAIA, W. M.; HARA, F. A. S.; CAVALHEIRO, W. C. S.; VENDRUSCOLO, J. Características hidrogeomorfométricas e análise temporal da cobertura na microbacia Acará, Amazônia Ocidental, Brasil. Geografía y Sistemas de Información Geográfica, v. 13, n. 20, Sección I: p. 1-22, 2021. Disponível em: https://revistageosig.wixsite.com/geosig/geosig-202021. Acesso em: 26 nov. 2021.

CAVALHEIRO, W. C. S. Avaliação ambiental como subsídio para o planejamento e gestão da sub-bacia do rio Branco, Rondônia. 2018. Dissertação (Mestrado em Ciências Ambientais) Universidade Federal de Rondônia, Rolim de Moura, RO, 2018. Disponível em: https://lemaflon.unir.br/pagina/exibir/17298. Acesso em: 22 nov. 2021.

CAVALHEIRO, W. C. S.; DONEGÁ, M. V. B.; SOUZA, T. W. S.; SANTOS JÚNIOR, N. R. F.; MAIA, E.; HARA, F. A. S.; VENDRUSCOLO, J. Uso de Geotecnologias na Caracterização Hidrogeomorfométrica e Análise temporal da cobertura do solo da microbacia Sabiá, Amazônia Ocidental, Brasil. Geografía y Sistemas de Información Geográfica, v. 13, n. 20, Sección I:p. 1-24, 2021. Disponível em: https://revistageosig.wixsite.com/geosig/geosig-20-2021. Acesso em: 26 nov. 2021.

CHRISTOFOLETTI, A. Geomorfologia. 2. ed. São Paulo, SP: Edgard Blucher, 1980.

CPRM - Serviço Geológico do Brasil. Geologia e recursos minerais do estado de Rondônia. Disponível

em: https://rigeo.cprm.gov.br/xmlui/bitstream/handle/doc/10277/sig rondonia.zip?sequence=10\&isAllowed =y. Acesso em: 12 jul. 2021.

DONEGÁ, M. V. B.; SOUZA, T. W. S.; LIMA, M. M.; PANZA, M. R.; PACHECO, F. M. P.; SARAIVA, J. G.; CAVALHEIRO, W. C. S.; VENDRUSCOLO, J. Caracterização hidrogeomorfométrica da microbacia 


\title{
RECIMA21 - REVISTA CIENTÍFICA MULTIDISCIPLINAR ISSN 2675-6218
}

\author{
CARACTERÍSTICAS HIDROGEOMORFOMÉTRICAS E DINÂMICA DA COBERTURA DO SOLO NA MICROBACIA \\ DO RIO ARIRANHA, AMAZÔNIA OCIDENTAL, BRASIL \\ Jhony Vendruscolo, Nilson Reinaldo Fernandes dos Santos Junior, Thaiza Martins de Macedo, Miquel Victor Batista Donegá, \\ João Ânderson Fulan, Renato Francisco da Silva Souza, Wanderson Cleiton Schmidt Cavalheiro
}

do rio Gavião, Amazônia Ocidental, Brasil. Research, Society and Development, v. 10, n. 1, e47910111844, 2021. DOI: http://dx.doi.org/10.33448/rsd-v10i1.11844

FAIRFULL, S.; WITHERIDGE, G. Why do Fish Need to Cross the Road? Fish Passage Requirements for Waterway Crossings. Sydney: NSW Fisheries, 2003.

FERREIRA, K. R.; ROCHA, J. D. S.; CAVALHEIRO, W. C. S.; CLIVATI, D.; SILVA, A. F.; SANTOS JÚNIOR, N. R. F.; VENDRUSCOLO, J. Características da paisagem da microbacia do rio Brilhante, Amazônia Ocidental, Brasil. Geografía y Sistemas de Información Geográfica, v. 13, n. 20, Sección I: p. 1-23, 2021. Disponível em: https://revistageosig.wixsite.com/geosig/geosig-20-2021. Acesso em: 26 nov. 2021.

FIETZ, C. R.; COMUNELLO, É.; CREMON, C.; DALACORT, R.; PEREIRA, S. B. Chuvas intensas no Estado de Mato Grosso. Dourados-MS: Embrapa Agropecuária Oeste, 2011.

FRANCA, R. R. Climatologia das chuvas em Rondônia - período 1981-2011. Revista Geografias, v. 11, n. 1, p. 44-58, 2015. DOI: https://doi.org/10.35699/2237-549X\%20..13392

GUERRA, A. J. T. Ravinas: processo de formação e desenvolvimento. Anuário do Instituto de Geociências, v. 20, p. 9-26, 1997.

HÖFIG, P.; ARAUJO-JUNIOR, C. F. Classes de declividade do terreno e potencial para mecanização no estado do Paraná. Coffee Science, v. 10, n. 2, p. 195-203, 2015. Disponível em: http://www.coffeescience.ufla.br/index.php/Coffeescience/article/view/833. Acesso em: 16 nov 2021.

HORTON, R. E. Drainage basin characteristics. Transactions, American Geophysical Union, v. 13, n. 1, p. 350-361, 1932. DOI: https://doi.org/10.1029/TR013i001p00350

IBGE - Instituto Brasileiro de Geografia e Estatística. Pesquisa agrícola municipal. Brasília: IBGE, 2021. Disponível em: https://sidra.ibge.gov.br. Acesso em: 16 nov. 2021.

INCRA - Instituto Nacional de Colonização e Reforma Agrária. Acervo fundiário. Disponível em: http://acervofundiario.incra.gov.br/acervo/acv.php. Acesso em: 15 maio 2018.

INPE - Instituto Nacional de Pesquisas Espaciais. Catálogo de Imagens. Disponível em: http://www.dgi.inpe.br/CDSR/. Acesso em: 01 nov. 2021.

LIMA, M. M.; DONEGÁ, M. V. B.; SOUZA, T. W. S.; PANZA, M. R.; PACHECO, F. M. P.; CAVALHEIRO, W. C. S.; HARA, F. A. S.; VENDRUSCOLO, J. Hidrogeomorfometria da microbacia do rio Paraíso: informações para auxiliar o manejo dos recursos naturais na Amazônia Ocidental. Research, Society and Development, v. 10, n. 3, p. e41410313367, 2021. DOI: http://dx.doi.org/10.33448/rsd$\underline{\text { v10i3.13367 }}$

LIMA JÚNIOR, J. C.; VIEIRA, W. L.; MACÊDO, K. G.; SOUZA, S. A.; NASCIMENTO, F. A. L. Determinação das características morfométricas da sub-bacia do Riacho Madeira Cortada, Quixelô, CE. VII Congresso Norte-Nordeste de Pesquisa e Inovação - CONNEPI. Anais... 1-7, 2012. Instituto Federal de Educação, Ciência e Tecnologia. Palmas, Brasil.

LOLLO, J. A. O uso da técnica de avaliação do terreno no processo de elaboração do mapeamento geotécnico: sistematização e aplicação na quadrícula de Campinas. 1995. Tese (Doutorado em Engenharia Geotécnica) - Universidade de São Paulo, São Carlos, SP, 1995.

MENDES, D. M.; COSTA, D. P.; ROSA, D. M.; VENDRUSCOLO, J.; CAVALHEIRO, W. C. S.; RODRIGUES, A. A. M. Morfometria e desmatamento da microbacia do rio Pirarara, Cacoal, Rondônia. 


\section{RECIMA21 - REVISTA CIENTÍFICA MULTIDISCIPLINAR ISSN 2675-6218}

CARACTERÍSTICAS HIDROGEOMORFOMÉTRICAS E DINÂMICA DA COBERTURA DO SOLO NA MICROBACIA DO RIO ARIRANHA, AMAZÔNIA OCIDENTAL, BRASIL Jhony Vendruscolo, Nilson Reinaldo Fernandes dos Santos Junior, Thaiza Martins de Macedo, Miquel Victor Batista Donegá, João Ânderson Fulan, Renato Francisco da Silva Souza, Wanderson Cleiton Schmidt Cavalheiro

Research, Society and Development, v. 10, n. 9, p. e3310917266, 2021. DOI: http://dx.doi.org/10.33448/rsd-v10i9.17266

MORETO, R. F.; MIRA, S. F.; SOARES, G. S.; SANTOS JUNIOR, N. R. F.; VENDRUSCOLO, J.; CAVALHEIRO, W. C. S.; STACHIW, R.; ROSA, D. M. Potencial das geotecnologias para monitoramento do impacto da colonização na floresta nativa na microbacia do rio Enganado, Amazônia Ocidental, Brasil. Revista Científica Multidisciplinar, v. 12, n. 7, p. e27588, 2021. DOI: http://dx.doi.org/10.47820/recima21.v2i7.588

MORETO, R. F.; MIRA, S. F.; SOARES, G. S.; SANTOS JUNIOR, N. R. F.; CAVALHEIRO, W. C. S.; VENDRUSCOLO, J.; ROSA, D. M. Características geométricas, topográficas e hidrográficas da microbacia do rio Enganado, região sul da Amazônia Ocidental. Revista Geográfica Venezolana, edição especial, p. 110-124, 2019. Disponível em: http://www.saber.ula.ve/handle/123456789/46149. Acesso em: 26 nov. 2021.

PACHECO, F. M. P.; DONEGÁ, M. V. B.; CAVALHEIRO, W. C. S.; FULAN, J. A.; ALVES, S. R. M.; HARA, F. A. S.; VENDRUSCOLO, J. Características gerais da microbacia do rio Capivara, Amazônia Ocidental, Brasil. Geografía y Sistemas de Información Geográfica, v. 13, n. 20, Sección I: p. 1-25, 2021. Disponível em: https://revistageosig.wixsite.com/geosig/geosig-20-2021. Acesso em: 26 nov. 2021.

PACHECO, F. M. P.; VENDRUSCOLO, J.; RAMOS, H. F.; RODRIGUES. A. A. M.; CAVALHEIRO, W. C. S; HARA, F. A. S.; ROCHA, K. J.; SILVA, G. N. Caracterização hidrogeomorfométrica da microbacia do Rio São Jorge, Rondônia, Brasil. Brazilian Journal of Development, v. 6, n. 1, p. 4219-4236, 2020. DOI: http://dx.doi.org/10.34117/bjdv6n1-301

PANZA, M. R.; DONEGÁ, M. V. B.; PACHECO, F. M. P.; NAGAO, E. O.; HARA, F. A. S.; CAVALHEIRO, W. C. S.; VENDRUSCOLO, J. Características da paisagem para manejo dos recursos naturais na microbacia do Rio Jacuri, Amazônia Ocidental, Brasil. Brazilian Journal of Development, v. 6, n. 12, p. 101532-101558, 2020. DOI: http://dx.doi.org/10.34117/bjdv6n12-592

PARÉDIO, R. F.; SILVA, G. C.; BARBOSA, D. D.; BARBOSA, T. P.; CAVALHEIRO, W. C. S.; SANTOS JÚNIOR, N. R. F.; HARA, F. A. S.; SOUZA, R. F. S.; VENDRUSCOLO, J. Características da paisagem para subsidiar o manejo dos recursos naturais na microbacia do rio Nova Gease, Amazônia Ocidental, Brasil. Geografía y Sistemas de Información Geográfica, v. 13, n. 20, Sección I: p. 1-23, 2021. Disponível em: https://revistageosig.wixsite.com/geosig/geosig-20-2021. Acesso em: 26 nov. 2021.

PARVIS, M. Drainage pattern significance in airphoto identification of soils and bedrocks. Photogrammetric Engineering, v. 16, p. 387-408, 1950. Disponível em: https://trid.trb.org/view/121329. Acesso em: 25 de novembro de 2021.

RIBEIRO, L.; KOPROSKI, L. P.; STOLLE, L.; LINGNAU, C.; SOARES, R. V.; BATISTA, A. C. Zoneamento de riscos de incêndios florestais para a Fazenda Experimental do Canguiri, Pinhais (PR). Floresta, v. 38, n. 3, p. 561-572, 2008. DOI: http://dx.doi.org/10.5380/rf.v38i3.12430

ROCHA, J. D. S.; FERREIRA, K. R.; CAVALHEIRO, W. C. S.; VENDRUSCOLO, J. A paisagem como indicador de manejo dos recursos naturais na microbacia do rio Alto Alegre, na Amazônia Ocidental. Geografía y Sistemas de Información Geográfica, v. 13, n. 20, Sección I: p. 1-23, 2021. Disponível em: https://revistageosig.wixsite.com/geosig/geosig-20-2021. Acesso em: 26 nov. 2021.

ROCHA, J. D. S.; SILVA, J. A. A lei da proteção da vegetação nativa e a efetividade para a recomposição das áreas de preservação permanente e reserva legal. Revista Geográfica Venezolana, 


\title{
RECIMA21 - REVISTA CIENTÍFICA MULTIDISCIPLINAR ISSN 2675-6218
}

\author{
CARACTERÍSTICAS HIDROGEOMORFOMÉTRICAS E DINÂMICA DA COBERTURA DO SOLO NA MICROBACIA \\ DO RIO ARIRANHA, AMAZÔNIA OCIDENTAL, BRASIL \\ Jhony Vendruscolo, Nilson Reinaldo Fernandes dos Santos Junior, Thaiza Martins de Macedo, Miquel Victor Batista Donegá, \\ João Ânderson Fulan, Renato Francisco da Silva Souza, Wanderson Cleiton Schmidt Cavalheiro
}

volume especial, p. 268-272, 2019. Disponível em: http://www.saber.ula.ve/handle/123456789/46149. Acesso em: 26 nov. 2021.

ROMERO, V.; FORMIGA, K. T. M.; MARCUZZO, F. F. N. Estudo hidromorfológico de bacia hidrográfica urbana em Goiânia/GO. Ciência e Natura, v. 39, n. 2, p. 320-340, 2017. DOI: http://dx.doi.org/10.5902/2179460X26411

SANCHES, G. K.; SANTOS JÚNIOR, N. R. F.; CARNEIRO, K. A. A.; CAVALHEIRO, W. C. S.; BALDEÓN, J. R. M.; VENDRUSCOLO, J. Características hidrogeomorfométricas e dinâmica da cobertura do solo na microbacia do rio Mandi-prata, Amazônia Ocidental, Brasil. Geografía y Sistemas de Información Geográfica, v. 13, n. 20, Sección I: p. 1-25, 2021. Disponível em: https://revistageosig.wixsite.com/geosig/geosig-20-2021. Acesso em: 26 nov. 2021.

SANTOS, A. M.; MOTA, V. C. Análise espacial dos usos e da cobertura da terra no pantanal dos rios Guaporé e Mamoré/Rondônia. Revista Brasileira de Geomática, v. 5, n. 3, p. 433-452, 2017. Disponível em: http://www.saber.ula.ve/handle/123456789/46149. Acesso em: 26 nov. 2021.

SANTOS, A. M.; TARGA, M. S.; BATISTA, G. T.; DIAS, N. W. Análise morfométrica das sub-bacias hidrográficas Perdizes e Fojo no município de Campos do Jordão, SP, Brasil. Revista Ambiente \& Água, v. 7, n. 3, p. 195-211, 2012. DOI: http://dx.doi.org/10.4136/1980-993X

SANTOS, H. G.; JACOMINE, P. K. T.; ANJOS, L. H. C.; OLIVEIRA, V. Á.; LUMBRERAS, J. F.; COELHO, M. R.; ALMEIDA, J. A.; ARAÚJO FILHO, J. C.; OLIVEIRA, J. B.; CUNHA, T. J. F. Sistema Brasileiro de Classificação do Solo. Brasília, DF: Sistema Brasileiro de Classificação de Solos, 2018.

SANTOS JÚNIOR, N. R. F.; SANTOS, C. M. M.; MAIA, E.; CAVALHEIRO, W. C. S.; ROSA, D. M.; VENDRUSCOLO, J. Caracterização da paisagem da microbacia do rio Lambari, Amazônia Ocidental, Brasil. Geografía y Sistemas de Información Geográfica, v. 13, n. 20, Sección I: p. 1-25, 2021. Disponível em: https://revistageosig.wixsite.com/geosig/geosig-20-2021. Acesso em: 26 nov. 2021.

SANTOS, L. P.; ROSA, D. M.; CAVALHEIRO, W. C. S.; VENDRUSCOLO, J.; ROSELL, E. C. F.; BIGGS, T.; STACHIW, R. Hidrogeomorfometria e índice de desmatamento da microbacia do rio Tinguí, Amazônia Ocidental, Brasil. Revista Geográfica Venezolana, edição especial, p. 40-56, 2019. Disponível em: http://www.saber.ula.ve/handle/123456789/46149. Acesso em: 26 nov. 2021.

SANTOS, R. D.; LEMOS, R. C.; SANTOS, H. G.; KER, J. C.; ANJOS, L. H. C.; SHIMIZU, S. H. Manual de descrição e coleta de solo no campo. Viçosa-MG: Sociedade Brasileira de Ciência do Solo, 2013.

SEDAM - Secretaria de Estado do Desenvolvimento Ambiental. Atlas Geoambiental de Rondônia. Porto Velho: SEDAM, 2002.

SILVA, A. F.; TRONCO, K. M. Q.; VENDRUSCOLO, J.; OLIVEIRA, J. N.; CAVALHEIRO, W. C. S.; ROSA, D. M.; STACHIW, R. Geoprocessamento aplicado a hidrogeomorfometria e índice de desflorestamento na microbacia do rio D’Alincourt, Amazônia Ocidental, Brasil. Revista Geográfica Venezolana, edição especial, p. 210-225, 2019. Disponível em: http://www.saber.ula.ve/handle/123456789/46149. Acesso em: 26 nov. 2021.

SILVA, C. J.; SOUSA, K. N. S.; IKEDA-CASTRILLONA, S. K.; LOPES, C. R. A.; NUNES, J. R. S.; CARNIELLO, M. A.; MARIOTTI, P. R.; LAZARO, W. L.; MORINI, A.; ZAGO, B. W.; FAÇANHA, C. L.; ALBERNAZ-SILVEIRA, R.; LOUREIRO, E.; VIANA, I. G.; OLIVEIRA, R. F.; CRUZ, W. J. A.; ARRUDA, J. C.; SANDER, N. L.; FREITAS JUNIOR, D. S.; PINTO, V. R.; LIMA, A. C.; JONGMAND, R. H. G. Biodiversity and its drivers and pressures of change in the wetlands of the Upper Paraguay-Guapore Ecotone, Mato Grosso (Brazil). Land Use Policy, v. 47, p. 163-178, 2015. DOI: https://doi.org/10.1590/S0103-40142015000200010 


\section{RECIMA21 - REVISTA CIENTÍFICA MULTIDISCIPLINAR ISSN 2675-6218}

CARACTERÍSTICAS HIDROGEOMORFOMÉTRICAS E DINÂMICA DA COBERTURA DO SOLO NA MICROBACIA DO RIO ARIRANHA, AMAZÔNIA OCIDENTAL, BRASIL Jhony Vendruscolo, Nilson Reinaldo Fernandes dos Santos Junior, Thaiza Martins de Macedo, Miquel Victor Batista Donegá, João Ânderson Fulan, Renato Francisco da Silva Souza, Wanderson Cleiton Schmidt Cavalheiro

SILVA, E. C.; PRAIA, W. M.; SANTOS, A. S.; CARDOSO, L. A. P.; HARA, F. A. S.; CAVALHEIRO, W. C. S.; VENDRUSCOLO, J. Características hidrogeomorfométricas da microbacia Três Galhos, Amazônia Ocidental, Brasil. Research, Society and Development, v. 10, n. 2, e20910212408, 2021a. DOI: http://dx.doi.org/10.33448/rsd-v10i2.12408

SILVA, G. C.; CAVALHEIRO, W. C. S.; SANTOS JÚNIOR, N. R. F.; HARA, F. A. S.; VENDRUSCOLO, J. Hidrogeomorfometria e dinâmica de cobertura do solo da microbacia do rio Segredo, Amazônia Ocidental, Brasil. Geografía y Sistemas de Información Geográfica, v. 13, n. 20, Sección I: p. 1-24, 2021b. Disponível em: https://revistageosig.wixsite.com/geosig/geosig-20-2021. Acesso em: 26 nov. 2021.

SILVA, Q. D. Mapeamento geomorfológico da Ilha do Maranhão. 2012. Tese (Doutorado em Geografia) - Universidade Estadual Paulista, Presidente Prudente, 2012.

SOARES, G. S.; SANTOS JÚNIOR, N. R. F.; MIRA, S. F.; MORETO, R. F.; CAVALHEIRO, W. C. S.; VENDRUSCOLO, J.; ROSA, D. M. Uso de plataforma SIG na caracterização morfométrica da microbacia do rio Santa Teresinha, Amazônia Ocidental, Brasil. Revista Geográfica Venezolana, edição especial, p. 84-95, 2019. Disponível em: http://www.saber.ula.ve/handle/123456789/46157. Acesso em: 22 ago. 2021.

TAMBOSI, L. R.; VIDAL, M. M.; FERRAZ, S. F. B.; METZGER, J. P. Funções eco-hidrológicas das florestas nativas e o Código Florestal. Estudos Avançados, v. 29, n. 84, 151-162, 2015. DOI: https://doi.org/10.1590/S0103-40142015000200010

TARGA, M. S.; BATISTA, G. T.; DINIZ, H. D.; DIAS, N. W.; MATOS, F. C. Urbanização e escoamento superficial na bacia hidrográfica do Igarapé Tucunduba, Belém, PA, Brasil. Revista Ambiente \& Água, v. 7, n. 2, p. 120-142, 2012. DOI: http://dx.doi.org/10.4136/1980-993X

VANNOTE, R. L.; MINSHALL, G. W.; CUMMINS, K. W.; SEDELL, J. R.; CUSHING, C. E. The river continuum concept. Canadian Journal of Fisheries and Aquatic Sciences, v. 37, p. 130-137, 1980. DOI: https://doi.org/10.1139/f80-017

VENDRUSCOLO, J.; CAVALHEIRO, W. C. S.; ROSA, D. M.; STACHIW, R.; VENDRUSCOLO, R.; SIQUEIRA, A. S. S.; BIGGS, T. Hidrogeomorfometria e desmatamento na microbacia do rio Manicoré, Amazônia Ocidental, Brasil. Revista Geográfica Venezolana, edição especial, p. 226-241, 2019. Disponível em: http://www.saber.ula.ve/handle/123456789/46149. Acesso em: 26 nov. 2021.

VENDRUSCOLO, J.; MEIRA FILHO, W. R.; SANTOS JUNIOR, N. R. F.; CAVALHEIRO, W. C. S.; SOUZA, E. F. M.; NAGAO, E. O.; FULAN, J. A. Análise da paisagem na microbacia Rio das Almas, Rondônia, Amazônia Ocidental, Brasil. Revista Científica Multidisciplinar, v .2, n. 11, p. e211982, 2021a. DOI: https://doi.org/10.47820/recima21.v2i11.982

VENDRUSCOLO, J.; PACHECO, F. M. P.; RAMOS, H. F.; CAVALHEIRO, W. C. S.; RODRIGUES. A. A. M. Hidrogeomorfometria da microbacia Alto Rio Escondido: informações para auxiliar o manejo dos recursos naturais na Amazônia ocidental. Brazilian Journal of Development, v. 6, n. 3, p. 9709-9730, 2020a. DOI: http://dx.doi.org/10.34117/bjdv6n3-011

VENDRUSCOLO, J.; PACHECO, F. M. P.; RODRIGUES, A. A. M.; RAMOS, H. F.; ROSA, D. M.; CAVALHEIRO, W. C. S. Características morfométricas da microbacia do Médio Rio Escondido, Amazônia Ocidental, Brasil. Brazilian Journal of Development, v. 6, n. 1, p. 565-585, 2020b. DOI: http://dx.doi.org/10.34117/bjdv6n1-040 


\section{RECIMA21 - REVISTA CIENTÍFICA MULTIDISCIPLINAR ISSN 2675-6218}

CARACTERÍSTICAS HIDROGEOMORFOMÉTRICAS E DINÂMICA DA COBERTURA DO SOLO NA MICROBACIA DO RIO ARIRANHA, AMAZÔNIA OCIDENTAL, BRASIL Jhony Vendruscolo, Nilson Reinaldo Fernandes dos Santos Junior, Thaiza Martins de Macedo, Miquel Victor Batista Donegá,
João Ânderson Fulan, Renato Francisco da Silva Souza, Wanderson Cleiton Schmidt Cavalheiro

VENDRUSCOLO, J.; SOUZA, E.; FERREIRA, K. R.; CAVALHEIRO, W. C. S.; HARA, F. A. S. Características da paisagem para subsidiar o manejo dos recursos naturais na microbacia Alto Rio Branco, Amazônia Ocidental, Brasil. Geografía y Sistemas de Información Geográfica, v. 13, n; 20 , Sección I: p. 1-21, 2021b. Disponível em: https://revistageosig.wixsite.com/geosig/geosig-20-2021. Acesso em: 26 nov. 2021.

VILLELA, S. M.; MATTOS, A. Hidrologia aplicada. São Paulo, SP: McGraw-Hill, 1975. 